\title{
Los movimientos sociales sí diseñan el territorio. Proceso de auto-organización en el área metropolitana de Valencia
}

\author{
Beatriz Giobellina \\ Observatorio AUPA (Agricultura Urbana, Periurbana y Agroecología) AER INTA Córdoba \\ (Instituto Nacional de Tecnología Agropecuaria y Programa Pro Huerta MDS); \\ INVIHAB - FAUD-UNC (Facultad Arquitectura, Urbanismo y Diseño, Universidad Nacional de Córdoba, Argentina) \\ b.giobellina@gmail.com
}

\begin{abstract}
Resumen. En sistemas de gobierno que no propician mecanismos democráticos y participativos para decidir, planificar y gestionar el territorio, los movimientos sociales, que suelen interactuar mediante redes auto organizadas, sí logran influir en sus procesos de conformación. Con más o menos éxito, la ciudadanía se hace oír y facilita u obstaculiza las actuaciones urbanísticas que benefician o perjudican sus intereses. Este artículo es resultado de una investigación doctoral realizada con metodologías participativas; uno de cuyos objetivos era estudiar la situación de la Huerta histórica del área metropolitana de Valencia y sus oportunidades de evolución hacia modelos territoriales más sostenibles y respetuosos de ese valioso patrimonio agrario, implicando a los actores sociales que la defienden desde hace varias décadas del avance del urbanismo. Entre las principales evidencias obtenidas está la constatación de la importancia de la acción de las plataformas ciudadanas (Salvem) en la conformación del territorio metropolitano en las últimas décadas, al mismo tiempo que la falta de visibilidad pública de sus aportes.
\end{abstract}

Palabras clave: periurbano, participación, complejidad, sustentabilidad, gobernanza, emergentes.

\begin{abstract}
In systems of government that do not use democratic and participatory means to decide, plan and manage the region, social movements (which tend to interact through self-organized networks) are able to manage to influence these formation processes. With variable success, citizens make themselves heard and will either facilitate or impede the planning activities that benefit or harm their interests. This article is the outcome of doctoral research with participatory methodologies. An objective of this research was to study the situation of the historic Huerta in the Valencia metropolitan area, and its opportunities for evolution towards a territory that is sustainable and responsible for this valuable urban-agricultural inheritance. This research involves social actors that for several decades have been defensive against urban progress. The main evidence obtained through this research is the finding of the importance of citizens' actions (Salvem) in recent decades that have shaped the metropolitan area, as well as the lack of public awareness of these efforts.
\end{abstract}

Keywords: Peri-urban, participation, complexity, sustainability, governance, emerging.

\section{Introducción}

¿Quién diseña y construye el territorio? ¿Podrían existir persistencias en un territorio de formas vitales históricas de relación comunidad-entorno natural? ¿Será posible vislumbrar un hilo de sabiduría colectiva local, que se transmite de generación en generación, cambiando de lenguaje y de aspecto, pero profundamente enraizado en la identidad de un pueblo? Estas y otras preguntas han surgido a partir del estudio de la gran huerta en la que 
ha crecido Valencia, últimamente, negando esa relación matricial y generosa con. el paisaje hidrológico y agrario que la rodea.

La comarca de la Huerta, que conformó lo que hoy se entiende por Valencia y su área metropolitana, es una región que desde hace un milenio fue conformando un modelo de sustentabilidad territorial muy sofisticado y ejemplar, constituido por una típica ciudad compacta mediterránea, rodeada por su área de aprovisionamiento: la Huerta histórica de origen andalusí, la Albufera y su porción de Mediterráneo. Pero sus fortalezas de sustentabilidad residían también en la forma inteligente en que sus actores sociales aprendieron a articularse, colaborar, tomar decisiones y enfrentar los conflictos de intereses en relación a la gestión del agua. No es casual que de esas tierras haya emergido el Tribunal de la Aguas, como forma independiente de manejo de los bienes comunes (en este caso: el sistema de regadío y el control del agua)

Este territorio ha sido producto de un proceso adaptativo, conflictivo y a la vez creativo de personas y sociedades que actuaron (y actúan) en un medio natural -con antropización creciente- en función de bases económicas de supervivencia, acumulación de capital y progreso. Es un proceso de construcción territorial inacabado, vivo, que si bien se ha iniciado hace más de doce siglos, continúa modificándose.

La historia de los movimientos sociales que construyeron este territorio no está escrita aún, y está invisibilizado y desvalorizado en el imaginario social su rol como protagonistas de la configuración del espacio metropolitano que observamos hoy. La sabiduría colaborativa de los agricultores, el esfuerzo por preservar la vida y sus condiciones de posibilidad, la rebelión y la resistencia pacífica ante el abuso de poder, la exigencia de respeto a su derecho de decidir, se muestran como conflictos aislados en un proceso histórico dilatado, de baja intensidad y poco representativos de la historia oficial de la Comunidad Valenciana.

Con este artículo deseamos contribuir a la recuperación de esta memoria histórica común, como estrategia frente a la tendencia hacia la fragmentación, el individualismo y la competencia por el poder. Entendemos como imprescindible el fortalecimiento de la conciencia del poder-hacer que tienen las personas cuando se movilizan contra el abuso del poder dominante, por la defensa de la vida y de su patrimonio cultural y natural.

Gran parte del material que se utiliza son resultados de investigación producto de una tesis doctoral $^{1}$ que se realizó con metodologías cualitativas y participativas, entre 2009 y 2011. Se trabajó con informantes claves, se realizaron talleres y jornadas con participación de representantes de diversos colectivos y organizaciones que defienden la huerta. También se realizaron más de 60 entrevistas a personas e instituciones, con el objetivo de recoger los diversos puntos de vista que constituyen la complejidad de las dinámicas territoriales históricas y actuales. Entre los productos más valiosos que podemos compartir se encuentra un relevamiento y mapeo de conflictos socio-ambientales distributivos, que emergieron del relato de las personas entrevistadas. Esto se aporta como una evidencia de que los esfuerzos de colectivos organizados en torno a una necesidad u objetivo común, disputan en el espacio político la capacidad de decidir y el modelo territorial que se conforma en la interrelación de intereses diversos y, muchas veces, antagónicos.

\footnotetext{
1 Título: La defensa del suelo agrícola de calidad como recurso finito y estratégico para la soberanía alimentaria y la sustentabilidad local y global. El caso de la huerta del gran Valencia.
} 


\section{Aprendiendo de Thomas Glick}

\subsection{Las bases auto organizadas y horizontales de la Huerta Andalusí y Medieval}

Analizando algunos aspectos de su pasado histórico, se puede comprender cómo ha evolucionado este sistema ciudad-huerta, y tal vez, algunas de las bases profundas de su supervivencia hasta nuestros días, básicamente en aquellos aspectos que hacen a las acciones colectivas para organizar el territorio frente a la adversidad (de la naturaleza o de los intereses político-económicos).

En reciente investigaciones, Thomas Glick (2011, p. 15) propone una explicación para el pasaje de la Huerta Andalusí a la de la Reconquista, en la que los nuevos ocupantes cristianos se apropiaron y amoldaron los usos y costumbres de los antiguos regantes, comprendiendo que eran las bases de la prosperidad de la región. Si en el origen de este inteligente territorio de regadío andalusí estaba la necesidad de incrementar la producción de alimentos para sostener la vida -gestionando participativamente el recurso limitado del agua-, en este nuevo período cristiano también primó la lógica de la supervivencia: una racionalidad adaptativa que trasformó sin destruir esencialmente lo precedente. Se crearon las comunidades de regantes. El sistema territorial pasó de la organización tribal a una organización jurídica o administración civil que coordinaba el conjunto de las Acequias, que no existía en el período Andalusí. La resolución de conflictos se realizaba en el marco de la tribu que poseía cada Acequia, a partir de la experiencia y sabiduría de sus ancianos; por lo que no había una comunidad de regantes tan compleja como se constituyó en el período posterior. Sobre la base Árabe y Bereber se montó una nueva forma organizacional que mezcló lo anterior con las prácticas de los gremios medievales de artesanos, dando lugar a las características que hoy conocemos más.

Hay numerosos estudios que, reconociendo la falta o insuficiente disponibilidad de documentación histórica, llegan a diversas conclusiones respecto a en qué punto situar el origen de las obras hidráulicas valencianas y, por lo tanto, a quién atribuirlas como su creador, o a qué tipo de "poder dominante" corresponden. No serían estas ideas las que explicarían el caso de la Huerta de Valencia, según Glick:

\footnotetext{
“...el trabajo de Borrull y sus seguidores fue posible por la antihistórica suposición de que solo una cierta clase de sociedad pudo haber producido el sistema de regadío valenciano. La posibilidad de que el sistema pudiera ser producto de un gradual acrecentamiento, el resultado de varias sociedades muy diferentes, nunca fue investigada de forma sistemática, con la consecuencia de que estructuras sociales similares fueron atribuidas a los romanos y a los musulmanes por los partidarios de cada bando, partiendo de la base del tipo de regadío que cada uno se suponía que había practicado. Así, lo que se conoce de la estructura social, política y económica de la España romana y musulmana, se da como explicación del completo desarrollo de su sistema de riegos. Las instituciones de distribución de aguas son fiel reflejo de la sociedad que las origina o practica. Cuando se comprenden pueden ayudar a nuestro conocimiento de la sociedad y la cultura. Pero no pueden ser deducidas de evidencias indirectas, basadas enteramente en restos arqueológicos, ni sobre teorías de obras públicas y poder administrativo." (Glick, 1988, p. 244. 245)
}

Por el contrario, si se analiza el sistema organizativo instituido en la Huerta se puede comprender la singularidad de esta organización horizontal y descentralizada, un sistema de capilaridad que cubría todo el territorio de un modo que podríamos llamar "democrático" (o al menos cooperativo y solidario) en oposición a verticalista o centralista. 
"En Valencia medieval (...) la administración del regadío era celular y descentralizada (el complejo açut-cequia constituía la unidad básica. Ya fuera la Comunidad de Regantes controlada por el municipio o autónoma, el grado de intervención de los regantes variaba poco, siendo en ambos casos considerable.” (Glick, 1988, p. 133)

La concepción jerarquizada parte de posturas ideológicas patriarcales que solo conciben los avances a partir del poder concentrado en pocas manos y desprecian las capacidades de las personas que actúan en forma colectiva, impulsadas por una necesidad o por un sentimiento o motivación fuerte. Desde la antigüedad las mayores obras han sido explicadas de esta forma: desde el poder plenipotenciario de un semidiós, y poco se ha invertido en pensar en las otras formas en que la humanidad ha dejado sus vestigios, por ejemplo, las catedrales góticas que requirieron siglos de construcción. Esta mirada forma parte de los mecanismos de dominación y autodominación que siempre están actuando para reforzar el modelo patriarcal y autoritario, donde se invisibilizan otras acciones cooperativas, colectivas, así como la diversidad humana.

\title{
2.2 La época moderna: memoria de las resistencias
}

En la época moderna hay evidentes persistencias, pero también se producen cambios significativos en los últimos dos siglos, desde el orden jurídico institucional, pasando por el tipo de cultivos que predomina, hasta llegar a un punto de bifurcación en el que, en estos momentos, se cuestiona la propia vitalidad y viabilidad de la Huerta Valenciana

\begin{abstract}
Los modelos o patrones medievales del uso del agua, las técnicas agrícolas y de riego, las formas de colonización de las zonas regadas, y las normas tradicionales de control social en los asuntos de riego, todo supervive prácticamente intacto en los tiempos modernos. Los profundos y sustanciales cambios en los viejos patrones de la agricultura de regadío, se producen principalmente en el siglo XIX, no en el tiempo de la Reconquista o de la expulsión de los moriscos. Los modelos de uso de las tierras en las áreas de regadío manifiestan considerable estabilidad hasta tiempos recientes; no fue hasta mitad del siglo XIX cuando las murallas de Valencia fueron derribadas y la ciudad empezó a traspasar sus límites invadiendo las zonas de regadío (huertas). Los perfiles económicos de la vida de la huerta mostraron también considerable continuidad. La más significativa ruptura con el pasado vino con la introducción a gran escala de nuevas cosechas y modernos métodos agrícolas en el siglo pasado. La dedicación de más y más tierras de cultivo del naranjo y la elevada productividad de cosechas de consumo tan general como el arroz, hecha posible por la introducción de los abonos, modificaron la orientación económica de la huerta, incrementando los mercados de exportación." (Glick, 1988, p. XVII)
\end{abstract}

Desde la segunda mitad del siglo XX, y ante el avance desenfrenado de un modelo inmobiliario de corte desarrollista, la Huerta es eliminada a trozos, así como desvalorizada la producción de alimentos para consumo local, por una ciudad que crece desprendiéndose del modelo de compacidad de la ciudad mediterránea, para incorporar las formas de ocupación del territorio extendidas, dispersas, de baja densidad e interconectadas por infraestructuras y vías de circulación donde predomina el automóvil. Glick es testigo de ese proceso:

"En los más de 30 años que han pasado desde la publicación de la primera versión en lengua inglesa de este libro -casi 15 de su primera edición castellana-, la fisonomía del regadío valenciano y de su historiografía ha sufrido cambios profundos. La misma Huerta de Valencia, eje central de este libro, está en vías de desaparición, como pone de manifiesto un corto recorrido por la zona. La contemplación del lamentable estado 
actual de los muchos rincones agradables de la Huerta -feliz combinación del paisaje natural y del artificio humano- que tuve la fortuna de poder historiar en mi juventud ha causado en mi una honda y negativa impresión. La importancia histórica de dichos enclaves, brutalmente agredido en las últimas décadas, y aún en la actualidad que hoy en día se ven agredidos -caso de Campanar y de la Punta d'en Silvestre-, se puede apreciar en estas páginas. También se han perdido estructuras históricas valiosas, como en el caso de un sinfín de molinos, o bien el azud de Rascanya, con su arco medieval (...) han sido aniquilados por un urbanismo desenfrenado." (Glick, 2003, p. 11)

A pesar de la hegemonía de ese modelo arrollador de ocupación y uso del suelo, en nuestras investigaciones observamos que una especie de "sistema inmunológico" de raíces antiguas emerge en el territorio, conformado por focos de resistencia ciudadana que actúan defensivamente en el área metropolitana de Valencia. Se oponen a diversas embestidas del poder político y económico, y disputan el modelo de desarrollo que se impone. Hasta la crisis de la primera década del siglo XXI prevalece el avance de un urbanismo insustentable, que excluyó a las organizaciones de la sociedad civil en la toma de decisiones sobre políticas territoriales. Por debajo, la acción de una importante cantidad de movimientos sociales, con sus éxitos y fracasos, muestran el alto grado de conflictividad socio-ambiental-territorial.

\section{El poder, miradas...}

Para para tender un puente conceptual entre la propuesta de Glick para comprender cómo se conformó la huerta andalusí y medieval, y sus posibles persistencias hasta nuestros días, podríamos analizar que coexisten (al menos) dos formas de observar y analizar (y en consecuencia, actuar) el espacio público, donde se manifiesta lo político. Una forma es dilemática, estructurada jerárquicamente y sólida (modelo patrístico, patriarcal y dominante). La otra forma es fluida, compleja, en movimiento y no jerárquica (más cercana al modelo matrístico y solidario).

\subsection{El Poder Dominante que genera la percepción de un escenario atomizado}

Cuando abordamos en las entrevistas la dimensión política y filosófica, desde una perspectiva convencional, observamos la percepción de un "poder político convencional". Se percibe un escenario atomizado, fragmentado, en el que no se integran ni el tiempo ni todas las dimensiones en juego, y donde una parte de los procesos históricos están invisibilizados. En ese escenario parece que solo ese orden vertical y hegemónico es posible, que no hay alternativas, y que la distribución del poder es una estructura rígida que no se puede cambiar. La organización del poder convencional actual funciona (y se percibe), no por casualidad, en un escenario de atomización, en el que el eje económico domina al eje político y no llega a conformar una malla permeable donde quepan todos los intereses de la ciudadanía ni sus posibilidades de actuar. Desde esa lectura, el ámbito político en el que se mueve la gente, particularmente los grupos activos en la defensa del territorio, no llega a coincidir orgánicamente con el ámbito donde se toman las decisiones, cooptado por los políticos profesionales o en ejercicio, y por los grupos económicos con gran capacidad de lobby. Prima la fragmentación (aunque puedan existir redes) y se consolidan los privilegios de quienes tiene mayor capacidad de presión y están más cerca de los poderes económicos y políticos. 

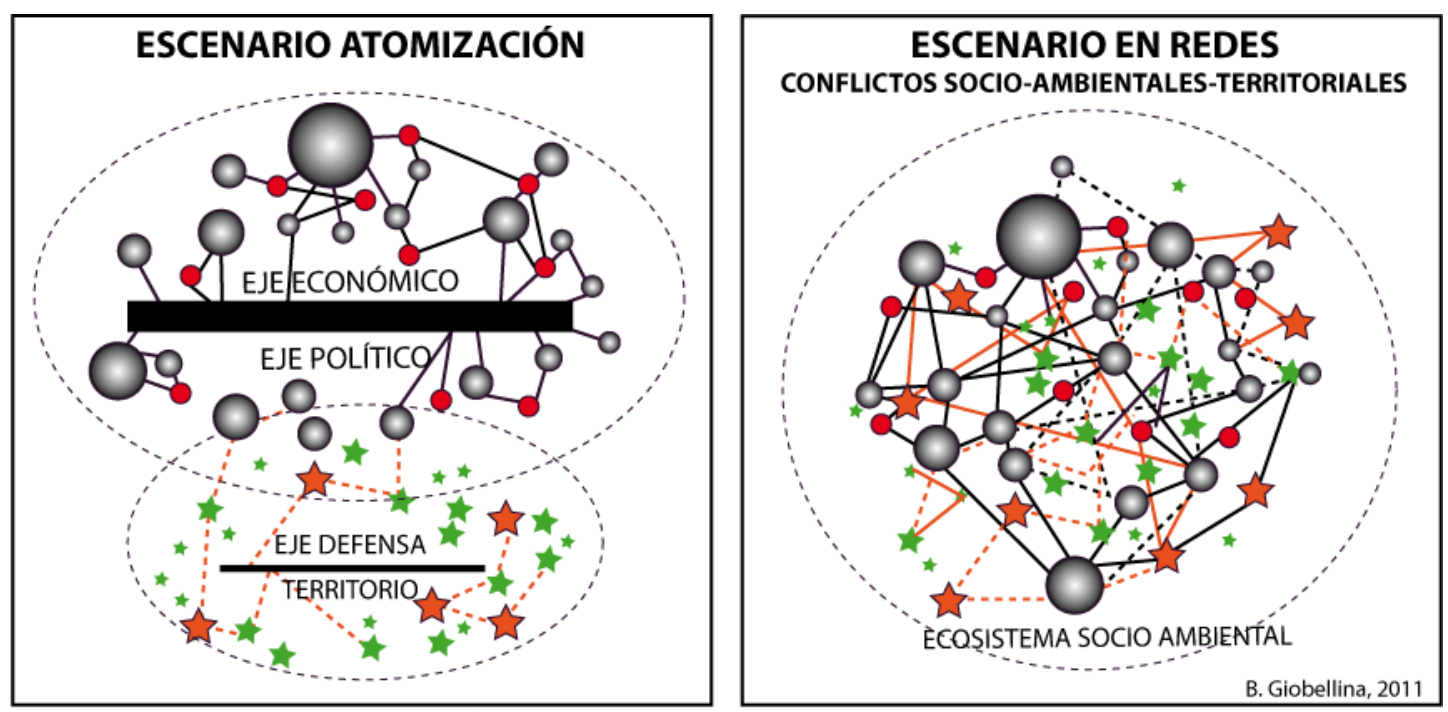

ThEDES DE AMBITO METROPOPOLITANO SOCIEDAD CIVIL LOCAL

CORPORACIÓN MUNICIPAL

GRUPOS PRESIÓN ECONÓMICA

Fig. 1.Escenarios de organización/percepción del poder

La realidad percibida (según las entrevistas realizadas entre 2009 y 2010) es muy desalentadora, porque está lejos de lo deseable a nivel de coordinación de políticas integrales y sustentables sobre el territorio, y mucho más lejos de la posibilidad de que la población, con toda su diversidad, participe democráticamente en la toma de decisiones.

\subsection{El poder-hacer que subyace en un escenario invisibilizado de redes}

Pero hay otra forma de mirar y entender estos espacios políticos: consiste en integrar en un proceso histórico (que presenta avances y retrocesos, éxitos y fracasos) todas las dimensiones que interactúan (social, económica, política y filosófica, ambiental, y del conocimiento y la cultura) y generan los conflictos, sin priorizar una de ellas (habitualmente es la económica, pero también la política o la física-territorial, que es la resultante visible) y negar o invisibilizar las restantes. También requiere fijar la atención en las relaciones y en los vínculos entre los/as actores sociales, teniendo en cuenta que estos vínculos pueden ser fuertes o débiles, visibles o menos visibles.

Cuando hablamos de la dimensión política desde la perspectiva de la sustentabilidad, "poder" se transforma en verbo: "poder-hacer", en términos de capacidades y creatividades de acción pública, donde las múltiples y diversas redes -la sociedad "enredada"-componen en la vida cotidiana su "buen vivir" dentro de los límites ecosistémicos "percibidos" de su entorno ambiental y político. Una organización política sustentable podría ser una democracia como ecosistema: "una democracia de todo lo viviente", en términos de Vandana Shiva, o un "democracia como ecosistemas donde todos los elementos tienen su función de creatividad” (y están entrelazados), en palabras de Tomás R. Villasante (2006). $\mathrm{Y}$, recordemos, los ecosistemas son de naturaleza compleja y funcionan en red.

Entre los obstáculos que se interponen para avanzar en esa dirección está la dificultad en la percepción de esas redes, de las relaciones que vinculan personas, organizaciones, dimensiones y escalas. Otro obstáculo es la forma de organizar una construcción democrática de consenso sobre cuáles son los límites que no se deben traspasar, así como los principios éticos que guían a la comunidad en sus relaciones internas y externas. Pero también existe la dificultad de romper dogmas, estereotipos y mitos, de ver procesos 
históricos dilatados en el tiempo, y, fundamentalmente, de valorar los avances y los logros que se han obtenidos, venciendo el sentimiento de derrota e impotencia (no-poder-hacer) que se impone en la construcción del orden establecido.

El orden establecido de múltiples dominaciones solo es posible si, además, existe la autodominación que "legitima" interiormente ese orden externo y ajeno a la persona, sus sentimientos y necesidades. Algunas de esas formas de dominación-autodominación se dan mediante mitos socialmente aceptados, mediante el otorgamiento del poder del conocimiento a unos en desmedro de otros/as, mediante la fragmentación y la atomización en partes que le quitan sentido al "todo". Hay muchos mecanismos, pero nos centraremos en la dificultad en la percepción de las relaciones que vinculan personas, organizaciones, dimensiones y escalas; y también los vínculos entre el presente y el pasado, que impiden comprender la historicidad de los procesos, su complejidad y que siempre es posible el poder-hacer, aunque lo alternativo esté invisibilizado.

\subsection{Fragmentaciones y desencuentros}

En el territorio metropolitano de Valencia, como resultado de las investigaciones, encontramos un mosaico de actores sociales entretejidos en una trama vital formada por redes ciudadanas, como se hizo evidente en unsociograma; pero a medida que se profundiza, se verifica que la trama es aún más amplia y compleja, que hay distintas miradas y motivaciones.

Del mismo modo que el poder convencional no es absoluto, sino dependiente de un nivel tolerable de tensión en su interrelación con la sociedad (gobernabilidad o gobernanza), el poder-hacer necesita de la relación con otro/a, necesita del vínculo interpersonal e intersujeto (y entre grupos); y el vínculo se construye mediante la comunicación. En los actos de comunicación se construye entendimiento, afecto, empatía, solidaridad, sentido de pertenencia, identidad, lealtad, consenso... Pero las comunidades suelen estar fragmentadas.

Las oligarquías políticas prefieren al ciudadano atomizado, aislado. Una forma de tiranía encubierta: no importa mucho que nos quieran más o menos, lo que importa es que no se quieran entre ellos, los ciudadanos activos. (Borja, 2011)

La fragmentación y la división entre las personas y grupos no necesariamente responden a rivalidades. La rivalidad y la competencia ya es una forma de relación, pero desde posiciones antagónicas. En el territorio metropolitano de Valencia, los tipos de fragmentación más generalizados que he observado podrían deberse a cuestiones muy simples y a otras de mayor complejidad sociológica.

\section{Miradas fragmentadas}

\subsection{La mirada de los/as "ajenos/as"}

Si bien hay muchos movimientos activos que defienden la Huerta o se oponen a un modelo de desarrollo injusto con las personas y con el medio ambiente, no llegan con su mensaje al público en general, a un público que los mira con indiferencia y no entiende (o comparte) 
sus reivindicaciones. Algunos/as entrevistados/as ajenos/as a la defensa del territorio han emitido este tipo de opiniones:

- "Los Salvem son la gente afectada." (ciudadano/a)

- "Los que defienden la huerta están metidos en grupos muy concretos, ecologistas... y muy minoritarios." (ciudadano/a)

- "Sé muy poco de los Salvem porque no tienen presencia a nivel mediático." (ciudadano/a)

- "Montar un Salvem es muy fácil, con una página web, ya está." (ciudadano/a)

- "Las voces que se escuchan de grupos pequeños pasan desapercibidas totalmente." (ciudadano/a)

- "En ciertos movimientos se mezcla demasiado los intereses de los partidos o las elecciones próximas.” (periodista)

- "No hemos oído hablar sobre la ILP ni de esos movimientos por la Huerta." (ciudadano/a)

- "Esos movimientos ni me van ni me vienen... no me llegan." (ciudadano/a)

\subsection{La mirada propia, de los "afines..."}

Estos son algunos testimonios de personas que están trabajando activamente y desde diversos ámbitos por la defensa de la Huerta y el Medio Ambiente, en el marco de un cambio de modelo de desarrollo económico y social. Aportan autocrítica y algunos puntos de vista que podrían generar cambios en las mecánicas organizativas y de acción de esos colectivos, aumentando las posibilidades del poder-hacer.

- "Muchas organizaciones pero poco trabajo conjunto (...) Hay muchísima gente que está trabajando, pero puntualmente y no se coordina. ¿Por qué no se ha logrado hacer una red? Porque cada colectivo tiene su idiosincrasia, su personalidad, sus personalismos... Urbanísticamente, con los pueblos y los barrios todavía podemos articularnos." (periodista)

- "Hemos pasado de una sociedad muy movilizada, al menos un sector, y hemos perdido ese engranaje." (periodista)

- "Los Salvemde defensa de la Huerta, salvo Catarroja, casi no han tenido repercusión social, en comparación con otros de la CV." (técnico/a administración)

- "Per L'Horta es el único referente de protección de la Huerta." (técnico/a administración)

- "Hay un incremento del nivel de conciencia de los ciudadanos que hacen surgir nuevas demandas en temas de Medio Ambiente, género, etc. Se piensa más allá de lo material, estamos en una etapa de reconfiguración de la sociedad." (académico/a)

- "Los Salvem están buscando unirse para construir redes poderosas." (ONG)

- "Las plataformas no tienen una "cara conocida" que se mueva por ellos." (periodista) 


\subsection{La mirada hacia (y desde) los ecologistas}

Los "ecologistas" son organizaciones que navegan en una escala más regional y global. Algunos se ven a sí mismos (y los ven) como "fuera" del sistema local, con otros intereses y objetivos no necesariamente relacionados con el "aquí y ahora", con la vida cotidiana, y, en este caso, con los intereses inmediatos de la Huerta. Acció Ecologista Agró podría ser una de las excepciones, ya que tiene una importante presencia en la historia de la defensa de la Huerta.

En la actualidad, coexisten tres grandes organizaciones: Ecologistas en Acción, con base principalmente en las comarcas de la provincia de Alacant, y menos en las de Castelló y Valencia; Acció Ecologista-Agró, en la ciudad de Valencia, L'Horta y Camp de Morvedre, con pequeños grupos en otras comarcas; y el GECEN (Grupo para el Estudio y Conservación de las Especies Naturales) tiene especial presencia en diversas comarcas de Castelló. Persisten muchos grupos locales estables o no, que siguen sin estar vinculados a ninguna de estas organizaciones. Hay que resaltar la existencia, dentro de Acció Ecologista-Agró, de dos colectivos dedicados específicamente a temas urbanos, como Vianants (ya desaparecido) y València en bici, todavía muy activo. (Torres Castejón, 2004)

En las entrevistas emergen estas ideas:

- "Está el tópico de siempre: "los ecologistas siempre denuncian, están en contra de..." (periodista)

- "La gente está relacionando ecología con sacrificio y no con calidad de vida. Por eso muchas veces se demoniza a los ecologistas." (periodista)

- “¡Ay! jotra vez los ecologistas... Siempre están en contra de todo!” (periodista)

- "La gente dice: "estos son los que siempre están en contra de... y no a favor de..." $(\mathrm{ONG})$

- "Muchas veces las informaciones ambientales han sido de calentarte la cabeza, no han sido positivas, agobian." (periodista)

- "Los ecologistas se desarrollaron en la época posfranquista y lucharon muy bien, pero llega un momento en que la gente se hace mayor y tienen otras prioridades familiares y laborales, ya no pueden seguir siendo militantes." (periodista)

- "Los ecologistas siempre hemos estado un poco de espaldas a la Huerta; no ha estado en nuestras prioridades tradicionales la defensa de estos paisajes. Hasta hace muy poco, pocos grupos ecologistas han planteado defender la Huerta; de hecho la ILP no tuvo su origen en movimientos ecologistas, que están preocupados más por la Albufera o por la central nuclear de Cofrentes. Pero aunque no se ocuparan directamente, todos los movimientos ecologistas han presentado alegaciones a los PGOU pidiendo que no se urbanizara más territorio.” (ONG)

- “Aparecen en los 70 bastantes grupos pero en la actualidad sobreviven solo dos: Acció Ecologista, que viene de los movimientos antinucleares, y Acció Ecologista-Agró, que viene de los conservacionistas, vinculado a la protección de las especies; estos, en los 80, se unifican. También está a nivel nacional Ecologistas en Acción, que en la CV atrae a otros pequeños grupos." (académico/a)

- "La naturaleza de los movimientos ecologistas de Valencia somos poco dados al tema cultural o paisajista, somos más de plumas y de bosques; pero tienen un rol en concienciar sobre el valor ambiental de la Huerta y sobre la compensación que hay que 
dar al agricultor por preservar ese valor. Tienen una opinión respetada en la sociedad." $(\mathrm{ONG})$

- "Los ecologistas estuvimos 30 años luchando por el territorio y no nos hicieron caso, de repente aparece Abusos Urbanísticos NO y empiezan estar en todos los medios y a tener un protagonismo público y político. Hay que reflexionar, la gente acaba acostumbrándose a la crítica constante y quita fuerza, hemos hecho demasiados salvem... el sistema acaba desactivando la oposición, asumiéndola como una parte del sistema." (ONG)

\subsection{Lecturas parciales y memoria borrosa (o borrada)}

Si bien se observan divisiones y fragmentaciones, sería un análisis incompleto y reduccionista si no observáramos también la trama de vínculos, fuertes y débiles, que se está tejiendo constantemente entre las personas y grupos sociales que están actuando desde hace al menos medio siglo, expresando su malestar y disconformidad frente a agresiones socio-ambientales territoriales. Esta es la característica más interesante mediante la cual se va construyendo el poder-bacer de una ciudadanía activa en el área metropolitana de Valencia; aunque en apariencia, desde lecturas parciales, y, probablemente, en la conciencia ciudadana, parezca débil y poco visible.

\footnotetext{
Conviene recordar de donde veníamos, no hace tantos años: del desierto del franquismo, una de cuyas tareas prioritarias y mejor logradas fue el arrasamiento de la sociedad civil. En el tardofranquismo empezamos a reconstruir ese tejido social (sindicatos clandestinos, asociaciones vecinales y culturales semilegales...), y en la Transición habíamos vivido una explosión de iniciativas ciudadanas, políticas y culturales de todo tipo, que reclamaban la participación en las decisiones municipales, y exigían pueblos y barrios con unas condiciones de vida dignas. (Torres Castejón, 2010)
}

La mayoría de los movimientos sociales identificados en el gran Valencia comparte, además de algún tipo de conflicto relacionado con el territorio y con el modelo económico, una actitud de insubordinación y rechazo a acciones jerárquicas y poco democráticas, cuando no autoritarias, de los poderes públicos. Se reclama, en general, el derecho a ser consultados y a que sus opiniones y necesidades sean tenidas en cuenta. Las tipologías de grupos y culturas variadas conviven y, en algunos casos, están muy articuladas por vínculos de solidaridad y apoyo. Existe una amplia gama de posiciones: conflictos de una comunidad o barrio por un PAI o un proyecto concreto de la Administración; actores más centrados en la Huerta como un concepto más globalizador, sea en la agricultura, en el patrimonio cultural o la defensa de la identidad; y también propuestas políticas que denuncian los impactos del neoliberalismo, la globalización, la injusticia ambiental y social, en escalas que transcienden el ámbito de lo local. Cabe señalar que éstas últimas no son las que predominan en los grupos que defienden la Huerta, pero sí en una amplia red de redes por la Soberanía Alimentaria, que está emergiendo en las tres provincias de la CV.

En la investigación se ha detectado muchas organizaciones y varios tipos de actores que defienden o han defendido el territorio, algunas han tenido grandes éxitos; muy pocas están atomizadas, dispersas o no tienen ninguna coordinación. Predominan las que tienen algún vínculo con otras, aunque parezca débil, porque en algún momento han llegado a formar conjuntos de acción, realizando marchas, campañas y solidarizándose unas con otras. 
También se han encontrado fuertes indicios de que se ha perdido (o está borrosa y muy fragmentada) la memoria histórica de lo que la acción ciudadana hizo en el último medio siglo y del apoyo que generaron.

- "No hay estudios sociológicos sobre los movimientos sociales que defienden el territorio, tal vez alguno puntual, pero nada más." (académico/a)

- "Hay que aprender a gestionar lo inesperado, la discrepancia, ya no valen los controles de los partidos; los ciudadanos se manifiestan en su individualidad en las luchas y manifiestan su discrepancia en redes de colectivos soberanos, independientes." (académico/a)

- "Las grandes luchas sociales en el territorio han sido luchas de mujeres con sus hijos y para sus hijos, desde el franquismo." (agricultor/a)

- "Al gobierno no le interesa que la gente se entere de los movimientos sociales." (académico/a)

\subsection{La fortaleza de los vínculos débiles: Salvem Catarroja}

- "Siempre somos los mismos." (ONG)

- "Estamos solos, pocos nos apoyan... la gente no sale de su casa por una movilización." $(\mathrm{ONG})$

Estas ideas están muy generalizadas entre los grupos y personas activas en los conflictos socio-ambientales-territoriales. Esto no coincidía con mi propia percepción a medida que avanzaba en las entrevistas, por lo que profundicé el análisis en uno de los grupos: la Plataforma Salvem Catarroja. Cuando hicimos la Linea del Tiempo, y reconstruimos su historia, les pedí que intentaran hacer memoria para cada situación, de quiénes más participaron y qué tipo de apoyo o relaciones mantuvieron con otras organizaciones o personas.

Al hacer esta actividad y ver el resultado de sus propias palabras, se sorprendieron, porque habían tenido siempre apoyos diversos: vecinos/as de Catarroja y de otros municipios metropolitanos que acuden a marchas, movilizaciones o firman peticiones; prensa escrita, televisión u otros medios que suelen publicar los comunicados y dan cobertura a eventos que organizan; otras plataformas y asociaciones con las que realizan actividades conjuntas; organismos y funcionarios públicos que cooperan para brindarles información, facilitarles trámites e incluso, apoyar sus demandas; algunos partidos políticos; colegios profesionales, algunos muy activos, como el de Arquitectos o el de Ingenieros de Caminos, Canales y Puertos; y hasta el Defensor del Pueblo y el Parlamento de la UE que ha recogido su caso en el Informe Auken.

Una primera reflexión es que puede haber una falsa expectativa de los/as activistas respecto al grado de movilización, compromiso y activismo que se espera de otros/as. No todos/as pueden tener el mismo grado de presencia en las actividades, y tampoco cumplen los mismos roles. También es posible que tenga vigencia el mito de la izquierda antigua de "movimientos de masa" fuertemente comprometidos con un objetivo común, una masa de iguales como contrapeso al poder concentrado; lo cual no se verifica en la historia más que en casos puntuales de revoluciones populares. Lo que sí es más frecuente y menos valorado son los pequeños cambios en la escala micro que pueden llegar a transformar la escala macro. ¿Cómo sucede esto? Básicamente mediante una trama de vínculos interpersonales 
que se va tejiendo con el tiempo y en procesos históricos, muchas veces en forma aleatoria, y que se puede verificar en la forma como se han relacionado los distintos grupos que emergieron ante los conflictos socio-ambientales territoriales del gran Valencia.

\footnotetext{
Muchas nociones intuitivas sobre la "fuerza" de un vínculo interpersonal deberían verse satisfechas por la siguiente definición: la fuerza de un vínculo es una (probablemente lineal) combinación del tiempo, la intensidad emocional, intimidad (confianza mutua) y los servicios recíprocos que caracterizan a dicho vínculo. Cada uno de estos aspectos es independiente del otro, aunque el conjunto esté altamente intracorrelacionado. (Granovetter, 1973)
}

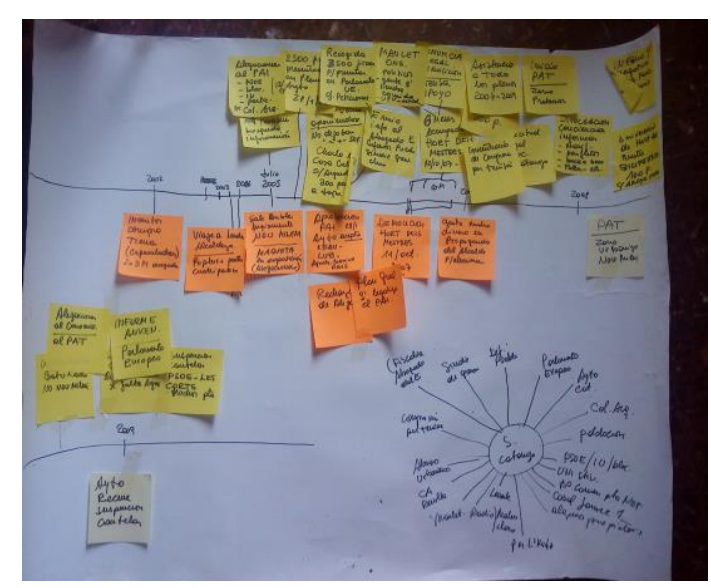

Fig. 2.Línea del Tiempo Salvem Catarroja

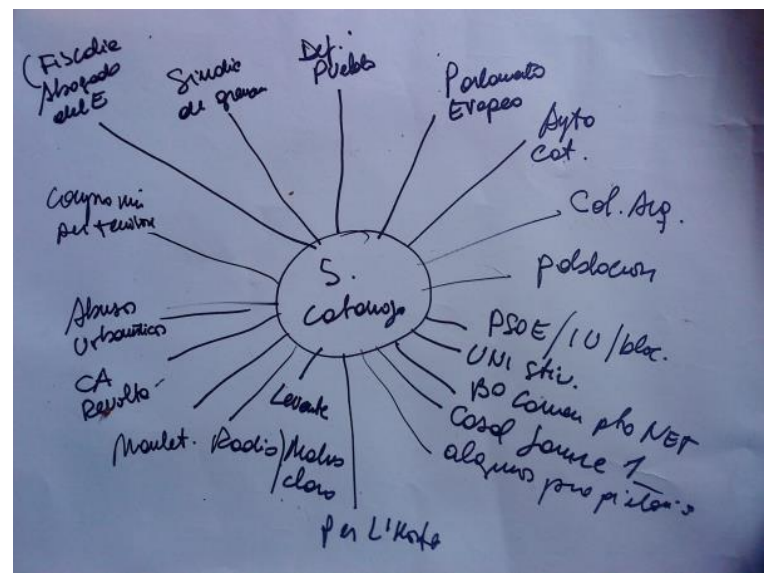

Fig. 3.Vínculos y apoyos recibidos

Este autor, al estudiar las dinámicas sociales de una comunidad, se centra en lo que acontece dentro de los confines de un grupo pequeño, y en cómo se puede llegar a las consecuencias macro de un aspecto de interacción a pequeña escala. De un modo u otro, es a través de estos sistemas vinculares de interacción a pequeña escala que se producen diversos fenómenos macro como la difusión, la movilidad social, la organización política y la cohesión social. Pero su mayor aporte es que destaca la fuerza de los vínculos débiles o el poder de unión de los lazos débiles. Los vínculos débiles se entienden como una relación informal, poco profunda, diferente a la amistad, los lazos familiares u otro tipo de afiliación grupal.

En el gráfico se puede ver cómo basta que exista un vínculo débil entre A y $\mathrm{B}$ (dos miembros de grupos cerrados o con relaciones fuertes que los unen), para que éste actúe como "puente" por el cuál puede fluir información entre todos los contactos de A y todos los contactos de B.

Granovetter también señala que en las grandes redes (sociedad real) suelen existir más de un vínculo entre miembros de un grupo a otro, y también que, aunque sean vínculos débiles, la información se difunde por todos los miembros que estén conectados con alguno de los miembros de cualquier grupo. Por lo tanto, las relaciones en la escala micro, pueden alcanzar dimensiones macro gracias a vínculos débiles, liberando del mito de que solo los vínculos fuertes entre grupos pueden hacerlo. Es más, el autor sostiene que los vínculos débiles son preferibles para unir a miembros de diferentes grupos pequeños, 
frente a los vínculos fuertes que tienden a estar concentrados en grupos particulares. La unión de los niveles micro y macro genera, desde este punto de vista, paradojas: los vínculos débiles, frecuentemente considerados como productores de alienación, son vistos aquí como indispensables para las oportunidades individuales y para su integración en las comunidades; los vínculos fuertes, que reproducen la unión local, llevan a una fragmentación total, porque dentro del grupo cada persona está unida a todos sus otros miembros pero no a los de afuera.

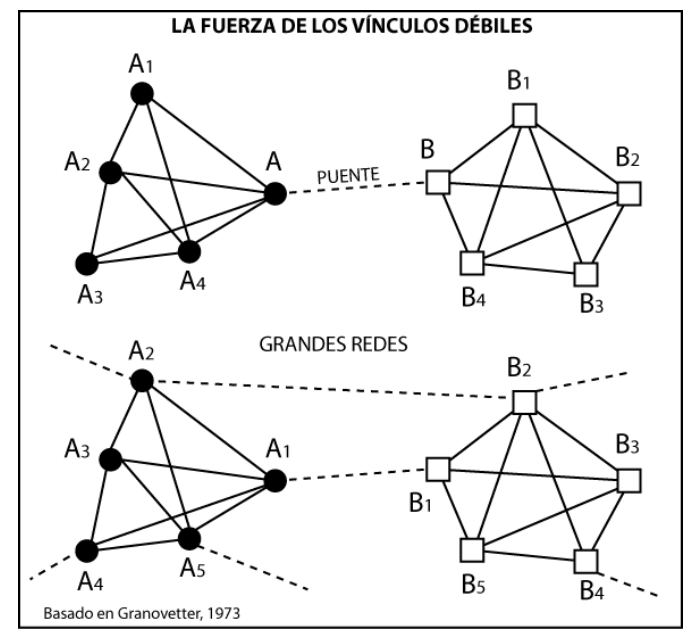

Fig. 4. La fuerza de los vínculos débiles, Granovetter 1973

La Web 2.0, las redes sociales, los movimientos democráticos desde "la primavera árabe al verano europeo", así lo confirmarían. Y también se podrían rastrear personas e influencias que van entretejiendo a los diferentes salvem y organizaciones sociales que han aparecido en el área metropolitana de Valencia. Estas tramas vinculares se producen mediante vínculos débiles (y fuertes) en una secuencia cronológica que se pone en evidencia con movimientos y protestas ciudadanas, al menos, desde los años 60, y emergen "espontáneamente" en diferentes momentos y puntos geográficos en conflicto a lo largo de medio siglo, como veremos en el siguiente apartado. Esto demostraría que hay una red articulada en torno a conflictos socio-económicos-territoriales. El "siempre somos los mismos" adquiere otra dimensión y significado, y el mito de sociedad atomizada, fragmentada e individualista, podría ser, como mínimo, errónea como generalización, o, más probable, una forma concreta de dominación desde el "pensamiento único".

\section{Los Salvem como desbordes creativos frente a los conflictos socio-ambientales- territoriales}

La forma, composición y objetivos de los movimiento ciudadanos están en constante evolución, y suele haber un retardo en cuanto a la comprensión, entendimiento y asimilación por parte del grueso de la sociedad sobre la innovación y la vanguardia social que algunos representan. Torres Castejón (2010) menciona que cuando aparecen los Salvem, en los años 90, por una confluencia de factores (mayor conciencia ambiental, pérdida de poder institucional de la izquierda, crecimiento del PP, creciente permeabilidad de la sociedad española hacia a las corrientes de pensamiento crítico y emancipatorio mundiales los movimientos antiglobalización o contra la guerra de Irak-, despertar al compromiso 
social de una nueva generación de jóvenes) fueron recibidos "con sorpresa o desconfianza no sólo desde las Administraciones públicas sino también por algunos partidos políticos que se consideran de izquierdas, e incluso desde ciertos colectivos sociales progresistas".

Los Salvem son un subproducto social del urbanismo arrollador neoliberal, una manifestación del "sistema inmunológico" local que reacciona frente a lo que consideran males y amenazas a una forma y calidad de vida. Surgen espontáneamente, en parte, como alternativa a las asociaciones vecinales que estaban cada vez más jerarquizadas, más burocratizadas y eran menos participativas. Es entonces cuando diversos colectivos se autoorganizan con una estructura horizontal, no jerárquica y pluralista; son apartidistas e incorporan a afectados directos e indirectos de proyectos urbanísticos y especulativos; se unen a la lucha personas de otros barrios o ámbitos, porque se sienten parte afectada de un modelo depredador (militantes de partidos políticos, ecologistas, organizaciones culturales, ciudadanía dispersa o sin filiación, etc.), generándose una solidaridad política con los directamente afectados: es el caso de La Punta, de Salvem el Cabañal, de Salvem Catarroja, entre muchos más. Cuando convocan manifestaciones se puede comprobar la diversidad que existe; son movimientos territoriales, no barriales.

\begin{abstract}
La experiencia de "Salvem el Botànic" (...) creó escuela en Valencia. Después de "Salvem el Botànic" (1994), nuevos colectivos surgieron en diversos barrios de la ciudad de Valencia, con mayor o menor fortuna. "Salvem el Pouet", en Campanar (1996), "Defensem La Punta", "Salvem el Cabanyal"(1998), "L'Atzucac" (1998), "Salvem Russafa" (1998)," Salvem L'Horta de Benimaclet" (2001)...como consecuencia de otras agresiones urbanísticas, pero también de iniciativas culturales nefastas o de la mala gestión de instituciones públicas (“Amics del IVAM...”). Muchos colectivos han fracasado, han tenido menos éxito, o una actividad más efímera, mientras que otros han conseguido éxitos, o continúan una lucha difícil pero aún no resuelta. Pero el camino está marcado, y en la ciudad de Valencia y su comarca cualquier grupo de afectados o implicados en un problema sabe ya que tienen derecho y posibilidad de organizarse para afrontarlo. (Torres Castejón, 2010)
\end{abstract}

En apoyo a la idea de autorganización horizontal y plural de estos colectivos se observa en su trayectoria: la solidaridad, la búsqueda del consenso o el reparto de tareas asumidas por voluntarios; la eliminación de caciquismos, dirigentes, líderes o cualquier estructura verticalista de poder; las relaciones interpersonales libres y fluidas; la calidad del trato humano y la confianza recíproca como base de las relaciones; el grado de compromiso y resistencia (hay que tener en cuenta que algunas luchas duran décadas); la participación desinteresada de profesionales y especialistas, principalmente en temas legales y urbanísticos; la capacidad de articularse con otros colectivos para realizar tareas conjuntas (marchas, comunicados, "caceroladas", alegaciones, jornadas, conferencias, etc.).

También es de destacar el importante rol de las mujeres en la lucha, uno de los casos emblemáticos en la actualidad es el de Salvem Catarroja, y también lo fue en el pasado el de La Punta, donde la resistencia social ha sido liderada por las mujeres:

\footnotetext{
Los hombres al principio pensaban que no se iba a poder hacer nada, que era una lucha perdida de antemano, y que si nos resistíamos haríamos el ridículo. Por eso nos han dejado hacer a las mujeres. Para ellos, hacer lo que hacemos es hacer el ridículo. Un corte de carretera para denunciar las bases de contenedores es hacer el ridículo. Ir a una manifestación es hacer el ridículo. Ir a una reunión es perder el tiempo. Entonces, no se implican.
} 
De la parte masculina de mi propia casa he recibido muchas presiones. Yo tuve que pasar casi seis meses con la lucha contra Iberdrola sin que en mi casa me hicieran el mínimo caso. Mi familia me veía como si estuviera loca ${ }^{2}$. Además, me miraban mal. Cualquier hombre de la pedanía, de esos que no tienen trellat, me decía : “¿Qué es lo que haces tú ahí en vez de estar limpiando tu casa ? ¡Si tú no sabes ni limpiar los platos!, ¡soguarra!"

Ahora, muchos hombres están con nosotras. Los hombres que están en la asociación que tiene 203 socios, nos defienden a capa y espada. (Carmen González, presidenta de la AAVV La Unificadora de La Punta, en Cabrejas, 1999)

Los salvem han tenido éxitos y derrotas, pero su mayor aporte es que han permitido concienciar a vecinos/as y dar visibilidad a los conflictos socio-ambientales que se manifestaban en el territorio. No sería descabellado pensar que una joven hija de los salvem podría ser la lucha por la Democracia real ya- o el Movimiento 15M, porque comparten el espíritu contestatario, ético, democrático, crítico, libertario, autoorganizado, pluralista y diverso.

\subsection{Mapas de conflictos socio-económicos-territoriales del Área Metropolitana de Valencia}

La ciudad, el territorio, los lugares públicos, son los espacios donde emerge lo político. Y lo político deja huellas en ellos. He visto la necesidad de contribuir a recuperar y visibilizar lo que fueron las luchas más importantes en el área metropolitana de Valencia, que están dejando huellas. En base a las entrevistas y con la colaboración de varias personas he confeccionado un par de mapas de casos que supusieron un conflicto territorial.

Mapa 1: He optado por tres clasificaciones de los mismos en función del grado de "éxito" en el logro de las reivindicaciones de los movimientos sociales, porque no solo es necesario recuperar la historia y la memoria, sino también la autoestima y la valoración de las luchas sociales. Lo que no se ve o no se nombra, suele no existir a nivel de la construcción simbólica de una comunidad. Hay que preguntarse por los mecanismos históricos responsables de la deshistoricización, en palabras de Pierre Bourdieu (2007), y añadiría: de invisibilización, porque esto no sucede por casualidad. La lógica de la tabula rasa que utilizan los colonizadores (antiguos y contemporáneos) y la mayoría de los urbanistas e ingenieros "modernos", también está actuando en el nivel consciente o inconsciente de las personas: suele comenzarse de cero, como si no existiera nada importante previo. Esto condena a repetir los mismos errores y a desperdiciar la experiencia social acumulada. También conduce al sentimiento de derrota y soledad.

La Valencia metropolitana que vemos hoy, es solo un fotograma de un proceso histórico complejo, en el que vienen fluyendo como un río fuerzas y energías que organizan, construyen (o destruyen) el territorio, en una dinámica continua política, económica y social, donde los deseos y objetivos de los diferentes grupos humanos a veces tienen cabida, y otras, son eliminados. Por eso considero que hay que recordar y nombrar los logros, lo que aún está en conflicto y necesita apoyo y estrategias renovadas, y lo que se ha perdido irremediablemente. Solo mirando el proceso histórico se puede comprender el presente e imaginar alternativas de futuro.

\footnotetext{
${ }^{2}$ Resulta recurrente en la historia que a las mujeres que no aceptan el orden impuesto y se rebelan, se las tilde de locas o neuróticas. Dos de los movimientos sociales más emblemáticos, que nacieron de lo más profundo de la condición y sentimiento femenino, son las "Madres de Plaza de Mayo" y las "Abuelas de Plaza de Mayo", en Argentina. Estas mujeres desafiaron a la dictadura militar (1976-1983) reclamando la aparición de sus hijos/as y nietos/as secuestrados. Los militares y los medios de comunicación se referían a ellas como "las locas de Plaza de Mayo".
} 
Los casos más importantes, los grandes éxitos (zonas verdes en el plano) que obtuvieron los movimientos sociales son, sin duda, el haber impedido que El Saler y la zona de la Albufera fuera convertido en un auténtico Benidorm, con un frente marítimo tapado por un muro de edificación; por el contrario, se ha logrado que se creara el Parque Natural El Saler.

Otros grandes éxitos han sido impedir la construcción de una autovía en el viejo Cauce del Turia, o que se creara el Parque Natural del Turia y que se protegiera unas 10.000 has. entre bosque y Huerta o el III Cinturón de Ronda y el Corredor Comarcal ${ }^{3}$ o lograr salvar el Botánic de la invasión de tres torres de viviendas y un hotel...

¿Podemos imaginar cómo sería el gran Valencia sin esos logros de la comunidad?

Es más, el hecho de que esté en marcha el PATH y que haya un "consenso de mínimos" de Huerta a proteger, es un logro de la constante lucha ciudadana.

Las zonas amarillas del mapa muestran que todavía existen muchos frentes abiertos para los movimientos ciudadanos, y comprueban que tienen sentido los temores frente a las amenazas que todavía se ciernen sobre la Huerta.

Las áreas rojas son las grandes pérdidas del campo popular: de los/as agricultores/as y de la comunidad en su conjunto, frente a las sucesivas oleadas de urbanismo extralimitado y especulativo.

Mapa 2: El área metropolitana de Valencia es un escenario de conflictos, y los movimientos ciudadanos forman parte de esa historia poco visible para una gran parte de la población. Las energías y las relaciones forman una matriz rizomática de vida, que interconecta mediante vínculos fuertes y débiles distintos episodios y sitios de la geografía valenciana, y está fluyendo en forma ininterrumpida. Yo hice una lectura de apenas un segmento de tiempo 1966-2011, pero sospecho que tiene raíces y eventos significativos, al menos, desde principio de siglo, y posiblemente de tiempos más remotos.

En ese período elegido, si posicionamos la emergencia de los casos en una línea de tiempo, se pueden observar, por un lado, que algunos logros llevaron mucho tiempo de conquista; por otro, una aglomeración de eventos en ciertos períodos, sobre todo a partir de 2005 en que hay un número mayor de casos en conflicto; y si están vigentes, eso quiere decir que no están condenados a un solo tipo de resolución.

\footnotetext{
3 "Hay que destacar que las importantes y documentadas movilizaciones contra este proyecto no han conseguido la retirada definitiva del mismo, ya que vuelve a reaparecer periódicamente, de manos de los mismos funcionarios que lo planearon o impulsaron hace 25 años. Esta persistencia de los mismos planteamientos (en este y en otros proyectos viarios), apenas moderados con un perfil viario ligeramente más bajo, evidencia la falta de asimilación por parte de los técnicos de nuevos planteamientos sobre la movilidad." (Torres Castejón, 2004, Anexos)
} 


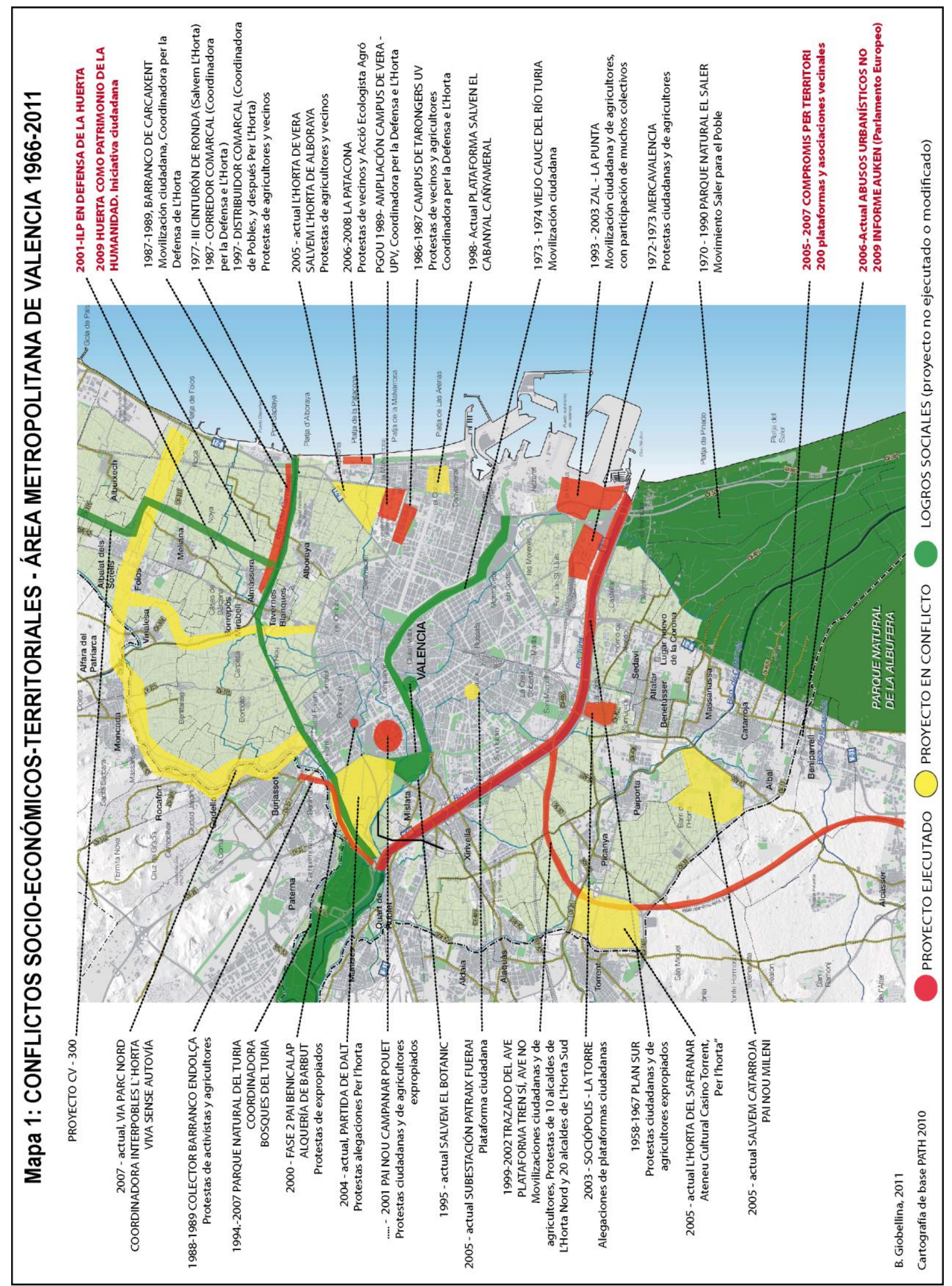




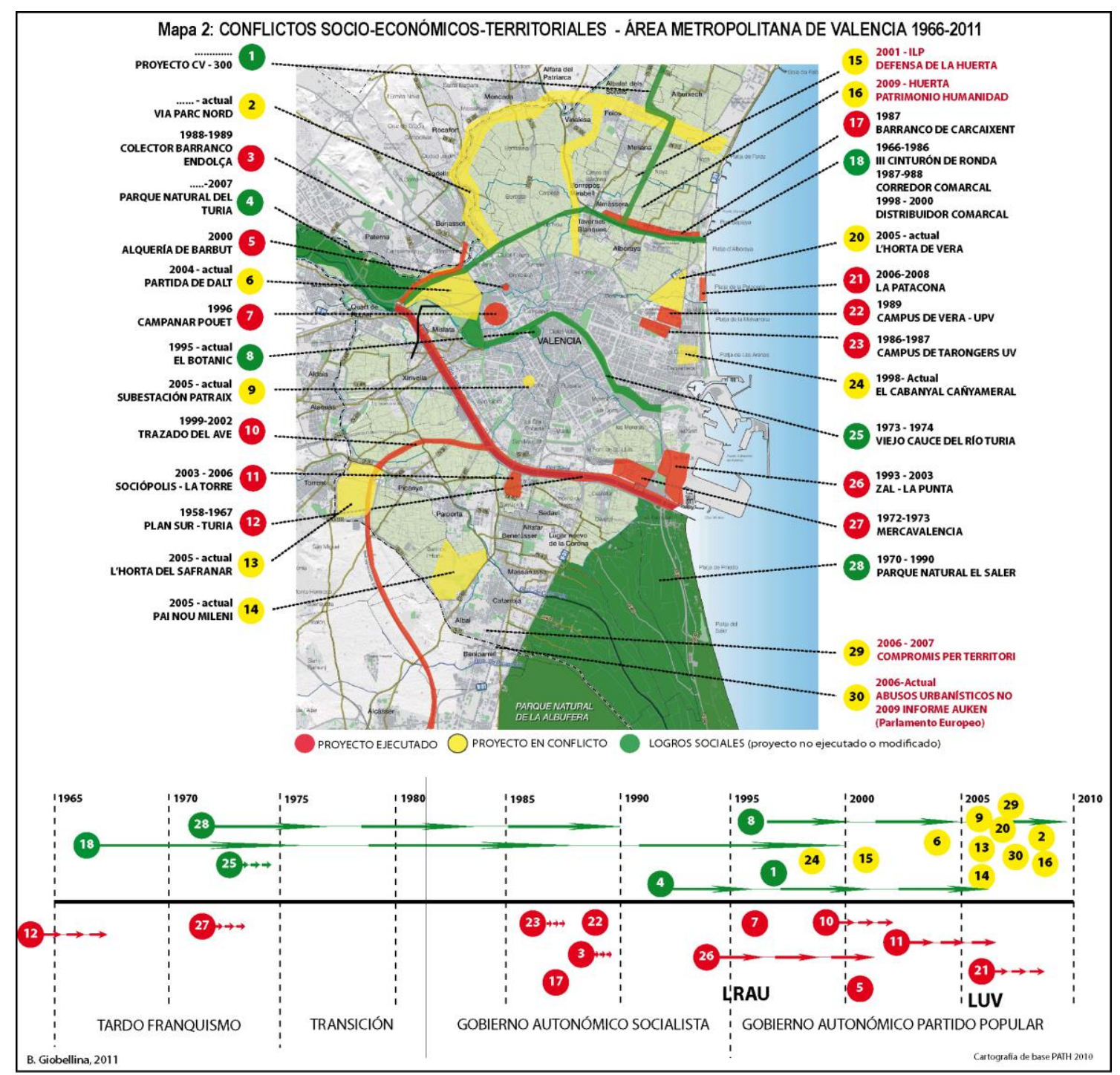

Para finalizar, estas lecturas del espacio político procuran promover reflexiones y más ejercicios de combinatorias e integración de conocimientos. Propongo este par de mapas como un medio más de recuperación, a partir de memorias fragmentadas, de una memoria colectiva, puesto que existen casos que aún no están registrados en el mapa o en el cuadro de los Salvem y las plataformas ciudadanas que desarrollo a continuación. Confío en que otras personas continúen con este trabajo de reconstrucción, ya que cada punto de color tiene muchas historias humanas que contar y experiencias de las que aprender.

En el siguiente cuadro están organizados en forma cronológica los proyectos de intervención en el territorio que generaron conflictos y una breve descripción de los colectivos sociales que participaron, así como de las acciones que realizaron. Es importante destacar que este material se ha ido desgranando de las entrevistas, y al tomar conciencia de la cantidad de casos y del conocimiento fragmentado que había de ellos, estimé oportuno sistematizar esta información para poder comprender la magnitud del proceso histórico ${ }^{4}$.

\footnotetext{
${ }^{4}$ Las fuentes de información utilizadas son: las entrevistas realizadas entre 2009 y 2011; Torres Castejón, 2004, 2004 Anexos, 2010 y otro material inédito cedido gentilmente por el autor; García, E. y Cabreja, M. 1996; AAVV- Colectivo Terra Crítica 2001-2007; Horta En Lluita, 2006; y las páginas Web de cada plataforma.
} 


\begin{tabular}{|c|c|}
\hline \multicolumn{2}{|r|}{$\begin{array}{l}\text { MOVIMIENTOS CIUDADANOS QUE ACTÚAN O HAN ACTUADO POR CONFLICTOS } \\
\text { SOCIO-ECONÓMICOS TERRITORIALES EN EL ÁREA METROPOLITANA DE valencia }\end{array}$} \\
\hline FECHA & PROYECTOS Y RESPUESTA SOCIAL \\
\hline $1958-1967$ & $\begin{array}{l}\text { PLAN SUR: Después de la Riada, se proyecta y construye el nuevo cauce del río Turia. Es uno de los peores } \\
\text { navajazos que se producen en la Huerta. Se elije esta opción entre tres proyectos. Se producen muchas } \\
\text { expropiaciones a agricultores, que resisten y protestan, pero es un período dictatorial, por lo que no llegan a } \\
\text { realizarse grandes movilizaciones. }\end{array}$ \\
\hline $\begin{array}{l}\text { Años } 70 \text { - } \\
\text { actual }\end{array}$ & $\begin{array}{l}\text { DEFENSA DE LA HUERTA (difusa): los conflictos socio-ambientales relacionados con la Huerta } \\
\text { comienzan en los } 70 \text { y van confluyendo las luchas de los agricultores, propietarios de tierra y con otros } \\
\text { sectores ciudadanos (ONG, plataformas, AAVV, Colegios profesionales, etc.). }\end{array}$ \\
\hline $1972-1973$ & $\begin{array}{l}\text { MERCAVALENCIA: es un fragmento más del desguace que se hizo de la Huerta de la Punta, que desde } \\
\text { los '60 se va sellando con cemento (Plan Sur y el nuevo encauzamiento del Turia, la autopista del Saler, la } \\
\text { depuradora de Pinedo, MercaValencia, las vías de ferrocarril Valencia-Tarragona, la ampliación sur del Puerto } \\
\text { que estropeó la playa de Pinedo, ZAL) En todos los casos se ha repetido el esquema: expropiaciones a } \\
\text { agricultores, que resisten y protestan, con el apoyo de algunos colectivos sociales. }\end{array}$ \\
\hline $1973-1974$ & $\begin{array}{l}\text { VIEJO CAUCE DEL RÍO TURIA:El llit del riu és nostre... la ciudadanía se moviliza: intelectuales, } \\
\text { técnicos y diversos colectivos presionan para impedir que se construya un proyecto de autovías en el viejo } \\
\text { cauce, que finalmente se convierte en un parque lineal, constituyendo una de las señas de identidad y } \\
\text { singularidades de Valencia actualmente. Si bien la ciudad perdió su río y una gran parte de la Huerta histórica, } \\
\text { la participación ciudadana recuperó el viejo cauce para el uso y disfrute de las personas, en lugar de } \\
\text { convertirlo en vías rápidas de circulación de tránsito automotor. }\end{array}$ \\
\hline $1970-1990$ & $\begin{array}{l}\text { EL SALER: En los años } 70 \text { se planifica la urbanización del Saler, esto genera un Movimiento Ciudadano: } \\
\text { Saler per al Poble para la defensa de la Albufera como Parque Natural. La presión ciudadana evitó } \\
\text { que avancen importantes proyectos por los que se urbanizaría toda la costa, con graves impactos en la } \\
\text { Albufera, en la biodiversidad y en el medio ambiente en general. La Albufera en un lugar de tránsito de } \\
\text { aves entre África y el Norte de Europa. } \\
\text { El Parque Natural El Saler fue creado en 1990, pero poca inversión se realizó para protegerlo, a pesar de que } \\
\text { se recibió dinero de la UE. Europa retiró el apoyo que había dado al Ayuntamiento y a la Consellería de } \\
\text { Medio Ambiente, al ver que su inversión económica se había reconducido hacia otros objetivos (todo el } \\
\text { dinero se había invertido para reconstruir las dunas, con paseos y chiringuitos). Después de } 20 \text { años de la } \\
\text { creación del parque, no se ha acabado la red de depuración de aguas y La Albufera sigue recibiendo } \\
\text { contaminación. }\end{array}$ \\
\hline $1972-1993$ & $\begin{array}{l}\text { III CINTURÓN: Es uno de los casos más emblemáticos de resistencia y éxito ciudadano frente a un } \\
\text { proyecto. La Administración tenía previsto ejecutar el III Cinturón de ronda, que iba a ser una vía de gran } \\
\text { capacidad, que atravesaría una de las zonas mejor conservadas de la huerta, al norte de la ciudad de Valencia. } \\
\text { La total oposición ciudadana ha imposibilitado durante más de } 30 \text { años la de esta infraestructura interurbana } \\
\text { para el transporte de carretera. El proyecto ha resucitado unas } 3 \text { veces: } 1972,1987 \text { y 1988, mediante nuevos } \\
\text { intentos de la administración para reiniciarlo. } \\
\text { La Associació d'Amics de 1'Horta, entidad constituida para oponerse al proyecto, contó con el apoyo de } \\
\text { la Comisión de Urbanismo del Colegio de Arquitectos de Valencia, Acció Ecologista Agró, ayuntamientos } \\
\text { y agricultores afectados, etc. Una coincidencia de diversos sectores sociales (profesionales, grupos } \\
\text { ecologistas, labradores afectados, asociaciones de vecinos...) se unieron para cuestionar la necesidad y la } \\
\text { conveniencia de este proyecto. Diversas manifestaciones de labradores (que llegaron a organizar columnas } \\
\text { de tractores hasta el mismo Ayuntamiento de Valencia) mostraron el rechazo de los principales afectados. }\end{array}$ \\
\hline 1988-1989 & $\begin{array}{l}\text { PGOU-1989 DE VALENCIA: la Coordinadora per la Defensa e L'Horta nuclea desde } 1988 \text { las } \\
\text { resistencias más activas, mediante una compleja alianza entre los intereses de los conservacionistas de la } \\
\text { Huerta de los pequeños agricultores, ciudadanos/as y ecologistas. Diversas organizaciones dan soporte a esta } \\
\text { Coordinadora: la Unió de Llauradors i Ramaders del País València, AAVV de poblaciones situadas en la } \\
\text { huerta agrícola y en la ciudad de Valencia, colectivos ecologistas y grupos profesionales de la clase media } \\
\text { urbana, algunos partidos políticos (EUPV y UPV). Estos grupos se oponen al nuevo PGOU aprobado por el } \\
\text { PSOE que prevé la destrucción de unas } 900 \text { ha de huerta agrícola (y unas } 1.250 \text { ha más en el futuro), cuando } \\
\text { la ciudad tiene un crecimiento demográfico nulo o en retroceso. También se planifica el Distribuidor } \\
\text { Comarcal, la ampliación de las instalaciones universitarias de la UPV, la canalización del Barranco de } \\
\text { Carcaixent, el Centro de transportes de Mercaderías, la Urbanización de Campanar y de l'Eixereta. }\end{array}$ \\
\hline $1993-2002$ & $\begin{array}{l}\text { III CORREDOR COMARCAL (reedición del III CINTURÓN): } \\
\text { El Ministerio de Fomento realizó un nuevo proyecto para dicho tramo viario, dentro de un Estudio } \\
\text { Informativo titulado "Ampliación de capacidad en la mitad norte del Bypass de Valencia (A7). Cierre Norte } \\
\text { de la V30". En el } 2^{\circ} \text { Plan de Carreteras de la Generalitat se reedita la nueva versión del proyecto de un } \\
\text { distribuidor comarcal por el norte, esta vez cambiando el trazado. En 1993, tuvo miles de alegaciones (más de } \\
\text { 6.000) de privados y públicas, algunas de los propios ayuntamientos que apoyaban el proyecto proponiendo } \\
\text { mejoras; pero otros (Godella, Alfara del Patriarca) proponen la total eliminación del mismo. El proyecto } \\
\text { implica un tránsito de unos } 20.000 \text { automóviles diarios en sus pasos por esos pueblos. Los agricultores se } \\
\text { oponen porque afecta seriamente la ancestral Acequia Real de Moncada, además de serios impactos } \\
\text { ambientales. } \\
\text { Diversos colectivos sociales de L'Horta Nord, así como los grupos ecologistas, reaccionaron con prontitud, } \\
\text { emprendiendo una campaña de sensibilización y movilización, que retomaba los argumentos que ya en los }\end{array}$ \\
\hline
\end{tabular}




\begin{tabular}{|c|c|}
\hline & $\begin{array}{l}\text { años } 70 \text {, y también en los } 80 \text {, paralizaron esta obra. Acció Ecologista Agrórealiza unas alegaciones donde } \\
\text { enumera efectos destructivos sobre } 200.000 \mathrm{~m} 2 \text { de huerta agrícola, la contaminación de los cultivos por los } \\
\text { vehículos, además de una gran cantidad de impactos socio-ambientales y de funcionamiento de la región. } \\
\text { Por otra parte, numerosos colectivos sociales de la ciudad y de L'Horta Nord constituyeron una Plataforma } \\
\text { denominada "Per un cinturód'Horta", desde la que se reclamaba, además de la paralización del proyecto, } \\
\text { diversas acciones para la protección de la huerta y la recuperación de sus valores ambientales y productivos. } \\
\text { La presión social fue suficiente para que el Ministerio retirara una vez más la propuesta, a la espera de un } \\
\text { mejor momento para su presentación. }\end{array}$ \\
\hline 1993-2003 & 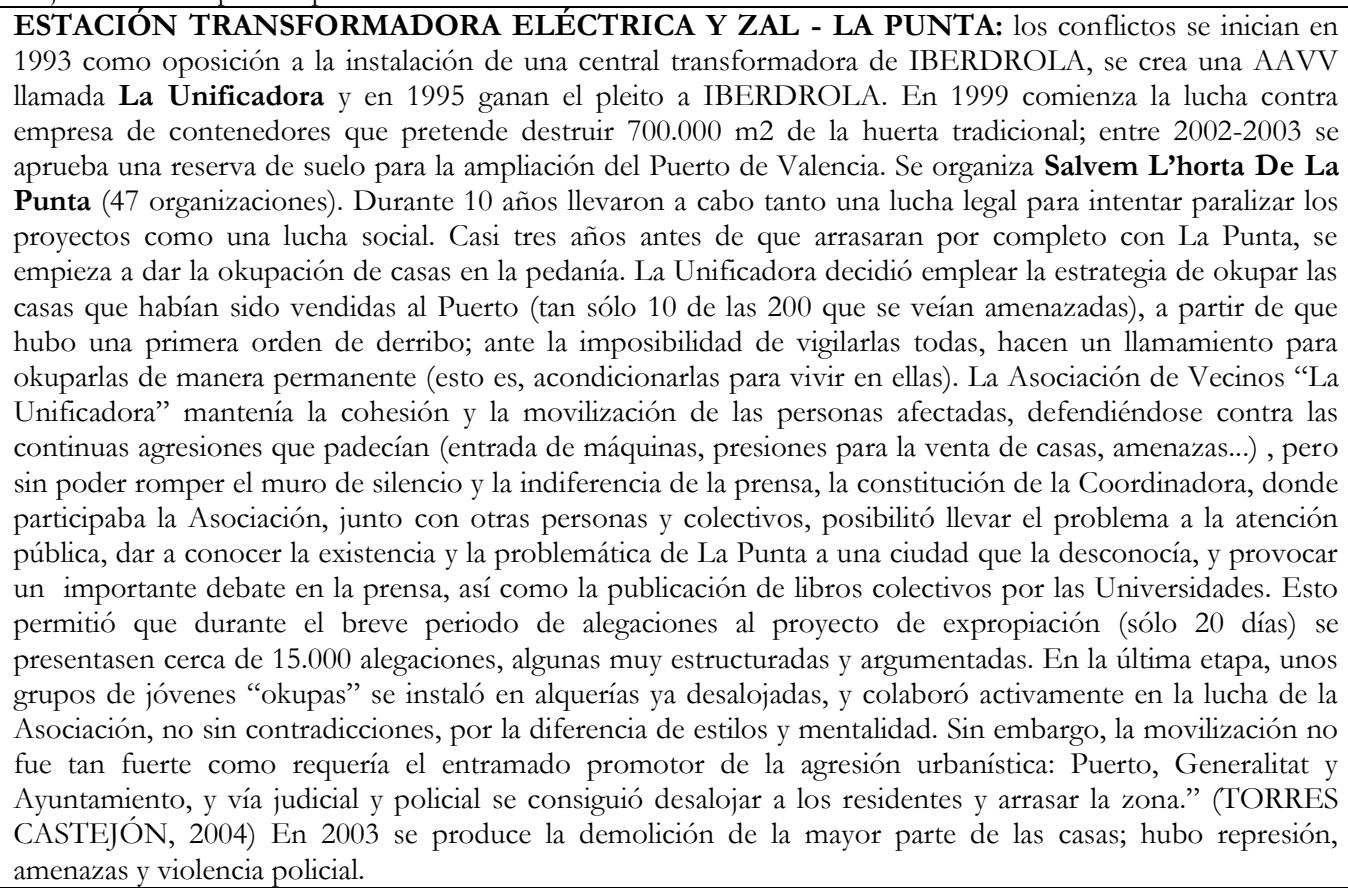 \\
\hline $1994-2006$ & $\begin{array}{l}\text { CREACIÓN DEL PARQUE NATURAL DEL TURIA: en } 1994 \text { se crea la Coordinadora Bosques del } \\
\text { Turia a raíz de un incendio, en la que participan AAVV y otras organizaciones de varios municipios que se } \\
\text { reúnen para intentar proteger un área de Huerta mediante la creación de un Parque Natural. En } 2006 \text { toman } \\
\text { conocimiento de que la Consellería de Territorio proyecta un PAI en Vallesa, y se recrudece la lucha social } \\
\text { para detener la urbanización. La Coordinadora se suma a la gran confrontación que tienen otros colectivos en } \\
\text { ese período contra la política urbanística, y tiene una fuerte presencia mediática. } \\
\text { En } 2006 \text { logran la creación del Parque Natural del Turia, en el que suman alrededor de } 4.660 \text { has. de bosque, } \\
\text { más } 5.000 \text { has. más de Huerta protegida nivel } 1 \text { (máxima protección), con lo que se logra preservar más de } \\
10.000 \text { has. En la actualidad la Coordinadora sigue trabajando porque al ser un espacio natural periurbano, } \\
\text { rodeado de edificación y autovías, sufre serios impactos medioambientales. Está formada por } 34 \\
\text { organizaciones de } 8 \text { de los } 9 \text { municipios que integran el parque. } \\
\text { Una experiencia integral interesante de huertos comunitarios que se está realizando dentro del Parque es el } \\
\text { Centro de Educación Ambiental Granja Julia, donde trabajan colectivos de desempleados, colectivos de } \\
\text { jóvenes del Barrio La Coma (un barrio con problemas sociales), familias de inmigrantes africanos y personas } \\
\text { afines. }\end{array}$ \\
\hline $\begin{array}{l}1995- \\
\text { actual }\end{array}$ & $\begin{array}{l}\text { EL BOTÁNICO: se constituye una Coordinadora Cívica: Salvem El Botánic para evitar que el } \\
\text { Ayuntamiento de Valencia ocupe irreversiblemente el antiguo patio ajardinado del Colegio de los Jesuitas } \\
\text { (Jardín Botánico de la Universidad de Valencia), desfigurando para siempre el paisaje del conjunto Botánico- } \\
\text { Jesuitas, considerado patrimonio de la ciudad. El proyecto consistía en construir } 3 \text { enormes torres (Hotel y } \\
\text { apartamentos). Estas acciones han contado con la participación y apoyo de una gran parte de la ciudadanía, } \\
\text { con lo que han logrado sus objetivos de erradicar el intento de urbanizar el Botánico. }\end{array}$ \\
\hline 1996 & $\begin{array}{l}\text { CAMPANAR: La plataforma Salvem el Pouet se oponía en } 1996 \text { a un macroproyecto urbanizador que } \\
\text { suponía la demolición de un conjunto de alquerías de la huerta de Campanar, algunas muy antiguas. No } \\
\text { consiguió paralizar las obras en marcha, debido a diversas razones: el tratarse de un proyecto urbanístico ya } \\
\text { muy avanzado, el ser un colectivo reducido, las pocas familias afectadas, el aislamiento respecto al barrio de } \\
\text { Campanar, la impunidad de las actuaciones de las empresas (con derribos no autorizados judicialmente)... } \\
\text { Pero su movilización sirvió para que en la segunda fase de la urbanización se rectificara el proyecto, } \\
\text { conservando un buen número de alquerías, algunas de ellas integradas como servicios o equipamientos. } \\
\text { (Torres Castejón, 2004) }\end{array}$ \\
\hline $\begin{array}{l}1998- \\
\text { actual }\end{array}$ & $\begin{array}{l}\text { PROLONGACIÓN AV. BLASCO IBANEZZ-CABANYAL: el proyecto provoca la destrucción de partes } \\
\text { de los antiguos barrios marítimos, afectando la forma de vida de una } 5.000 \text { personas; por lo que se constituye } \\
\text { una Plataforma Salvem Cabanyal-Canyameral de la que forman parte diversas organizaciones sociales y } \\
\text { ciudadano/as de diversos ciudades de la CV, que se sienten damnificadas por la posible pérdida de ese } \\
\text { patrimonio urbano. Es una de las luchas más antiguas que aún no están resueltas. La plataforma ha recurrido } \\
\text { a todas las instancias judiciales: autonómica, estatal y europea. }\end{array}$ \\
\hline
\end{tabular}




\begin{tabular}{|c|c|}
\hline $\begin{array}{l}1998-1999 \\
\text { (continúa } \\
\text { actualmente } \\
\text { ) }\end{array}$ & $\begin{array}{l}\text { PER L'HORTA: Las movilizaciones contra la nueva reaparición del Corredor Comarcal, dieron lugar a la } \\
\text { consolidación de una Coordinadora ciudadana que, con el nombre de "Per L'Horta", se ha constituido en } \\
\text { un referente social de bastante importancia, en el área de Valencia. Es un nodo de red y participa, apoya o } \\
\text { colabora con prácticamente todas las organizaciones que están en los conflictos socio-ambientales- } \\
\text { territoriales del área metropolitana de Valencia. }\end{array}$ \\
\hline $\begin{array}{l}1998- \\
\text { actual }\end{array}$ & $\begin{array}{l}\text { BARRIO RUSSAFA: en el que habitan unas } 24.000 \text { personas, se organizó la plataforma Salvem Russafa, } \\
\text { como iniciativa para recuperar, conservar y preservar el patrimonio natural, arquitectónico y artístico, mejorar } \\
\text { el barrio y participar de las decisiones que se tomaban sobre él. Entre otras acciones, en } 1999 \text { el colectivo } \\
\text { solicitaba que el Ayuntamiento se haga cargo de los jardines del palacete Monfort, situado en la calle de Pedro } \\
\text { III el Grande para destinarlo a zona verde y uso social. Los vecinos ya habían recogido más de } 5.000 \text { firmas } \\
\text { para salvar "el único jardín que quedaba en el barrio", en el que vivían cerca de } 6.000 \text { ancianos. Russafa carece } \\
\text { de dotaciones escolares, deportivas, atención a la tercera edad y tiene muchas otras necesidades. También } \\
\text { reclamaron al ayuntamiento que retire el proyecto de aparcamiento en el parque Manuel Granero y respete } \\
\text { los árboles y que comience las obras de construcción del colegio. Trabajaron con otros colectivos para evitar } \\
\text { el avance del racismo y de manifestaciones Skin-Neofascistas y Neonazis de la extrema derecha (España } \\
2000 \text { ) en el un barrio con mucha población inmigrante. }\end{array}$ \\
\hline $1999-2002$ & $\begin{array}{l}\text { TRAZADO DEL AVE MADRID-VALENCIA: el proyecto, cuyo trazado fue cambiado varias veces por } \\
\text { la oposición de ayuntamientos y de los colectivos ciudadanos, acabó realizándose. En 1999, } 20 \text { Alcaldes de } \\
\text { L'Horta Sud se unen para reclamar al Gobierno que modifique el trazado del nuevo acceso ferroviario. Una } \\
\text { parte de los colectivos de numerosas comarcas valencianas, que se oponían al trazado previsto para las } \\
\text { nuevas líneas de Alta Velocidad se aglutinó en una plataforma cuyo lema era "Tren Si, AVEno". En } 2001 \\
\text { casi } 40 \text { organizaciones adhieren a un manifiesto elaborado por la plataforma. } \\
\text { Está pendiente el trazado Valencia-Barcelona, que pasará por L'Horta Nord. } 10 \text { localidades de estaban } \\
\text { afectadas por el trazado del AVE que plantea el Ministerio de Fomento y se solicita un nuevo estudio con el } \\
\text { fin de lograr un trazado alternativo que tenga en cuenta las necesidades de todos los municipios. La negativa a } \\
\text { que el tren pase por la huerta es rotunda. El trazado propuesto por Fomento tiene un ancho de entre } 20 \text { y } 40 \\
\text { metros y discurrirá por } 25 \text { kilómetros de l'Horta Nord, afectando a los términos de diez poblaciones de la } \\
\text { comarca. Las localidades afectadas directamente por la infraestructura son Puçol, El Puig, La Pobla de } \\
\text { Farnals, Massamagrell, Massalfassar, AlbalatdelsSorells, Albuixech, Meliana, Foios y Alboraya. También el } \\
\text { resto de localidades de l'Horta Nord se han mostrado en contra del trazado planteado. } \\
\text { Como resultado de las acciones de protesta se lograron mejoras en el proyecto. No sólo se luchó contra los } \\
\text { efectos negativos de los nuevos proyectos, sino que se plantearon alternativas, y se elabora una propuesta de } \\
\text { contenidos para un Plan Valenciano de Ferrocarriles, intentando crear una corriente de opinión que influya (a } \\
\text { escala de País Valenciano y también estatal, dentro de una Coordinadora) en las decisiones referentes al } \\
\text { futuro modelo ferroviario. }\end{array}$ \\
\hline 2001 & $\begin{array}{l}\text { ILP- INICIATIVA LEGISLATIVA POPULAR EN DEFENSA DE LA HUERTA: la Plataforma } \\
\text { Per L'Horta impulsa una recogida de firmas para presentar un proyecto de ley a las Cortes Valencianas para } \\
\text { lograr la protección de la Huerta. Consigue reunir } 117.000 \text { firmas (cuando lo mínimo necesario eran } 50.000 \text { ). } \\
\text { Al presentarlas, las Cortes no llegaron a tratarla, aduciendo que ya tenían un proyecto en marcha para } \\
\text { proteger la Huerta. Muchos años después se comienza a gestionar el PATH, cuyo origen puede situarse en } \\
\text { aquella ILP. }\end{array}$ \\
\hline $2003-2006$ & $\begin{array}{l}\text { SOCIÓPOLIS - LA TORRE: se presentan alegaciones por la destrucción casi completade la Huerta de La } \\
\text { Torre (Plataforma Per L'Horta y otros) pero no se logra paralizar el polémico proyecto de Sociópolis, } \\
\text { un plan urbanístico impulsado la Generalitat, (Rafael Blasco), para la construcción de cerca de } 2.800 \\
\text { viviendas en la pedanía de La Torre, en la Huerta del Ayuntamiento de Valencia. } \\
\text { "Sociópolisfué presentado en la Bienal de Valencia del año } 2003 \text {, en un proyecto en el participaron } 13 \\
\text { arquitectos internacionales. En él se proponía un nuevo modelo de desarrollo urbano en el que la viviendas y } \\
\text { los equipamientos multifuncionales se integraban en un entorno agrícola, siguiendo el modelo del "hortulus" } \\
\text { mediterráneo. Tras su presentación se decidió realizar un primer barrio de } 2.800 \text { viviendas protegidas (650 en } \\
\text { regimen de alquiler), al sur de la ciudad de Valencia, en la pedanía de La Torre, situado en torno al nuevo } \\
\text { cauce del rió Turia, en una superficie de alrededor de } 350.000 \text { m2. En este proyecto la transformación urbana } \\
\text { viene guiada por la voluntad de proteger el máximo de superficie de "huerta" } \\
\text { http://www.sociopolis.net/web/sociopolis.php }\end{array}$ \\
\hline $\begin{array}{l}2003- \\
\text { actual }\end{array}$ & $\begin{array}{l}\text { ABUSOS URBANÍSTICOS NO: Es una asociación no lucrativa establecida legalmente en Denia cuyo } \\
\text { ámbito de acción se extiende por toda la Comunidad Valenciana; agrupa a residentes europeos y valencianos, } \\
\text { en su mayor parte propietarios de fincas afectadas por PAIs y que no quieren ser expropiados, debido a que } \\
\text { las tensiones sociales se han disparado en todo el territorio de la CV desde la promulgación de LRAU. Los } \\
\text { afectados por PAIs suman decenas de miles de personas. Se han presentado } 15.000 \text { quejas por parte de } \\
\text { Abusos Urbanísticos No a la Comisión de Peticiones del Parlamento Europeo, que han obligado a la } \\
\text { modificación de la LRAU y a la aprobación de una nueva Ley Urbanística, pero que mantiene los puntos } \\
\text { fundamentales de la anterior. } \\
\text { La primera petición a la UE fue en mayo de 2003. En setiembre de } 2004 \text { se le escribe una carta al rey de } \\
\text { España denunciando la situación de abusos. En noviembre de } 2004 \text { se escribe otra carta al ministro de } \\
\text { Asuntos Exteriores de España y en Noviembre de } 2005 \text { a la Ministra de Vivienda. } \\
\text { Ha conseguido que el Parlamento Europeo (PE) realice los siguientes informes: } 13 \text { de diciembre de 2005, } \\
\text { Informe Fourtou: Resolución del PE sobre las alegaciones de aplicación abusiva de la Ley Reguladora de la } \\
\text { Actividad Urbanística (LRAU) y sus repercusiones para los ciudadanos europeos; Mayo/Junio de 2006: } \\
\text { Parlamento Europeo, Comisión de Peticiones: Informe Anual [...] y Resolucion Aprobada Junio de 2006; } 8\end{array}$ \\
\hline
\end{tabular}




\begin{tabular}{|c|c|}
\hline & $\begin{array}{l}\text { de marzo 2007: Informe de la visita a España de la Comisión de Peticiones del PE; } 26 \text { de marzo de } \\
\text { 2009 Informe Auken aprobado por el PE. } \\
\text { Su demandas también están recogidas en: } \\
\text { - Informes de Greenpeace (Destrucción a toda costa) de 2005, 2006, 2007, } 2009 \text { y 2010. Estos informes } \\
\text { de la ONG se realizan con la contribución de las denuncias de particulares. } \\
\text { - Sindic de Greuges, en los informes de 2004, 2005, } 2006 \text { y } 2007 . \\
\text { - Informes delDefensor del Pueblo Español } \\
\text { - Consejo de Derechos Humanos de la ONU: Informe sobre la Vivienda en España (julio de 2007). } \\
\text { Toda esta información puede ser consultada en: http://www.abusos-no.org/ }\end{array}$ \\
\hline $\begin{array}{l}2004 \\
\text { actual }\end{array}$ & $\begin{array}{l}\text { PARTIDA DE DALT- CAMPANAR: es una de las zonas de Huerta mejor conservadas de la ciudad de } \\
\text { Valencia, y está actualmente amenazada por la construcción de infraestructuras (cierre de la Ronda Nord que } \\
\text { pretende partirla por la mitad, además de intereses inmobiliarios que podrían sellar más superficie). Per } \\
\text { L’Horta denuncia la intención de degradarla deliberadamente por parte de las autoridades; allí se ha } \\
\text { localizado durante mucho tiempo el "hipermercado de la droga". La plataforma ha presentado proyectos para } \\
\text { crear allí un parque agrario urbano. }\end{array}$ \\
\hline $\begin{array}{l}2005- \\
\text { actual }\end{array}$ & $\begin{array}{l}\text { L'HORTA DE VERA: la plataforma Salvem L'horta de Alboraia es un colectivo formado por un } \\
\text { centenar de agricultores y vecinos de la Huerta de Vera, propietarios de unos } 400.000 \mathrm{~m} 2 \text { de tierra, que se } \\
\text { oponen a un proyecto del Ayuntamiento de expropiación para construir un centro comercial, viviendas de } \\
\text { lujo y otros negocios. El proyecto pretende trasladar al interior al hipermercado Alcampo, situado al frente } \\
\text { del mar, y urbanizar una de las Huertas más ricas y productivas, donde se concentra el cultivo de chufa con } \\
\text { alta modernización y tecnologización. Los agricultores son empresarios de éxito, algunos ya habían sido } \\
\text { expropiados cuando se construyeron las Universidades. Hasta el momento el proyecto está detenido. }\end{array}$ \\
\hline $2005-2007$ & $\begin{array}{l}\text { COMPROMIS PEL TERRITORI, es una red de redes autoorganizada. Conformó un movimiento que } \\
\text { coordinó más de } 200 \text { organizaciones vecinales de toda la CV entre } 2005 \text { y } 2007 \text {. Realizó múltiples acciones en } \\
\text { la que participaron todo tipo de personas y organizaciones, preocupadas y afectadas porque el territorio } \\
\text { valenciano estaba padeciendo el mayor conjunto de agresiones de su historia reciente. Se sumaron a } \\
\text { Compromís personas de los pueblos y las ciudades de todo el país y de todas las comarcas, tanto de la costa } \\
\text { como del interior, logrando movilizar en una sola manifestación a más de } 25.000 \text { personas. } \\
\text { Se caracterizó por innovar en una forma de articulación de la participación ciudadana mediante una } \\
\text { organización horizontal, donde se tomaban decisiones en asambleas abiertas, y se trabajaba en comisiones } \\
\text { técnicas de apoyo. Si bien en este momento no está activa, puede reactivarse porque es una red de redes que } \\
\text { está interconectada. }\end{array}$ \\
\hline $\begin{array}{l}2005 \\
\text { actual }\end{array}$ & $\begin{array}{l}\text { SUBESTACIÓN PATRAIX: La Plataforma Subestació Patraix Fora o Pro traslado de la Subestación } \\
\text { de Patraix, en representación de los vecinos de este barrio, han luchado por la no instalación de una } \\
\text { subestación de transformación eléctrica ST Patraix a } 2.000 \text { metros de distancia de zonas habitadas, por } \\
\text { considerarla molesta y peligrosa. A pesar de las quejas del vecindario, la construyeron, pero la lucha ciudadana } \\
\text { y una explosión de la misma hizo que consiguieran su cierre. Ahora solicitan que la subestación y el cable que } \\
\text { le suministrará electricidad a } 220.000 \text { voltios sean trasladados lejos de las zonas residenciales. Está } \\
\text { demostrada la relación entre la exposición continuada a campos electromagnéticos, como los que producirá la } \\
\text { subestación, y diversas enfermedades (leucemia, otros tipos de cáncer, problemas del sistema inmunológico, } \\
\text { depresión, etc.). Ya hay varias sentencias en España obligando al traslado de transformadores de potencia } \\
\text { muy inferior por haberse producido varios casos de leucemia y otros tipos de cáncer entre los vecinos. }\end{array}$ \\
\hline $\begin{array}{l}2007- \\
\text { actual }\end{array}$ & $\begin{array}{l}\text { VIA PARC NORD: Con la reaparición de la nueva versión del corredor intercomarcal, se crea la } \\
\text { Coordinadora Interpobles L'Horta Viva Sense Autovías, que aglutina AAVV y colectivos de todos los } \\
\text { pueblos afectados por el proyecto (Godella, Rocafort, Massarrojos, Moncada, Burjasot, etc.) }\end{array}$ \\
\hline $\begin{array}{l}2002- \\
\text { actual }\end{array}$ & $\begin{array}{l}\text { PAI NOU MILENI: Desde } 2002 \text { se detectan movimientos especulativos de compra de tierras agrícolas en } \\
\text { donde luego se conocerá que se proyecta un nuevo PAI en el municipio de Catarroja. En } 2005 \text { recién se hace } \\
\text { público el proyecto y un grupo de vecinos de Catarroja y propietarios de tierras en la Huerta afectados, se } \\
\text { reúnen en la Plataforma Salvem Catarroja para manifestar su inconformidad con el } \\
\text { megaproyecto urbanístico «Nou Mil·lenni», que quiere imponer el ayuntamiento y la Consellería de Vivienda, } \\
\text { promovido por una empresa Llanera S.A.. Es uno de los proyectos urbanísticos actuales de mayor } \\
\text { envergadura en la Comunidad Valenciana, por el que se pretende construir } 12.000 \text { viviendas ( } 7.000 \text { son } \\
\text { de protección oficial) repartidas en } 60 \text { torres de entre } 10 \text { y } 25 \text { alturas, que podrían albergar cerca de } 40.000 \\
\text { habitantes más en una localidad que tenía una población, en } 2009 \text {, de } 27.035 \text { habitantes (estimaciones de } \\
\text { población del INE, 2010), con } 6.267 \text { viviendas principales, } 1.320 \text { no principales, de las cuales } 1.247 \text { están } \\
\text { desocupadas (INE). Los habitantes del municipio expresaron la necesidad de aumentar la dotación de } \\
\text { servicios públicos (áreas verdes y sanidad) y de continuar con un crecimiento sostenible, valorando muy } \\
\text { positivamente el intentar preservar su carácter de pueblo y rechazando el convertirse en ciudad dormitorio. } \\
\text { Este emprendimiento inmobiliario ha sido recurrido ante la justicia nacional y ante el Parlamento Europeo } \\
\text { por organizaciones de vecinos, y también fue paralizado por el Tribunal Superior de Justicia, que estima } \\
\text { que no ha quedado acreditada la disponibilidad «presente y futura» de recursos hídricos suficientes para } \\
\text { atender la demanda de agua que generará la nueva actuación, basado en un Informe desfavorable de la } \\
\text { Confederación Hidrográfica del Júcar (13/02/2008). La empresa Llanera S.A. ha estado en concurso de } \\
\text { acreedores entre } 2007-2009 \text {, logrando que se aceptara su plan de viabilidad económica en base a la potencial } \\
\text { ejecución este proyecto urbanístico. }\end{array}$ \\
\hline $2006-2008$ & $\begin{array}{l}\text { LA PATACONA: Un grupo de vecinos y Ecologistas en Acción llevan años tratando de que se reconozca } \\
\text { la ilegalidad de unas torres construidas en suelo que tenía una clasificación que impedía que las levantasen. La } \\
\text { Ley de Costas dice que en los primeros } 100 \text { metros que hay desde la línea de deslinde al interior no se puede }\end{array}$ \\
\hline
\end{tabular}




\begin{tabular}{|c|c|}
\hline & $\begin{array}{l}\text { construir vivienda salvo que se trate de suelo urbano o tenga un plan parcial. En } 2008 \text { el Tribunal Supremo } \\
\text { les dio la razón y condenó al entramado empresarial a indemnizar a sus antiguos clientes. Pero hay quien no } \\
\text { se quedó satisfecho y las torres siguen en pie. }\end{array}$ \\
\hline 2009 & $\begin{array}{l}\text { INICIATIVA HUERTA COMO PATRIMONIO DE LA HUMANIDAD: Si bien aún no se ha } \\
\text { logrado que la UNESCO incorpore a la totalidad de la Huerta histórica en su catálogo patrimonial, si se ha } \\
\text { logrado que lo haga con el Tribunal de las Aguas de Valencia, conocido también como Tribunal de la Vega de } \\
\text { Valencia. Este tribunal es un Jurado de Riegos encargado de dirimir los conflictos por el agua de riego entre } \\
\text { los agricultores de las Comunidades de Regantes de las acequias que forman parte de él (Quart, Benàger i } \\
\text { Faitanar, Tormos, Mislata, Mestalla, Favara, Rascanya y Rovella). El conjunto de estas acequias forman la } \\
\text { denominada Vega de Valencia, sobre la que tiene jurisdicción el Tribunal, que, junto a la Acequia Real de } \\
\text { Moncada, con jurisdicción aparte, forman la Huerta de Valencia. En septiembre de } 2009 \text { es designado } \\
\text { Patrimonio Cultural Inmaterial de la Humanidad. }\end{array}$ \\
\hline $\begin{array}{l}2006- \\
\text { actual }\end{array}$ & $\begin{array}{l}\text { UN MAR DE BANDERAS PROTESTA: Además de los casos expuestos en el cuadro, existen otras } \\
\text { organizaciones en conflicto: Acció y Reflexió Ciutadana per València-ARC; Salvem L'Horta de Benimaclet; } \\
\text { AAVV del parc i jardí de la Plaça José M M Orense; AAVV Orriols-Rascanya; Assemblea d' Immigrants; } \\
\text { Comissió d' Afectats per la Clínica Virgen del Consuelo; Coordinadora Ciutat-Vella; Plataforma Anti- } \\
\text { Abocador Poble Nou; Plataforma per Russafa; Plataforma per una Vivenda Digna; Plataforma Pro- } \\
\text { polideportivo Benicalap-Campanar-Beniferri; Recuperem La Model; Salvem Tabacalera; XuquerViu; etc. }\end{array}$ \\
\hline
\end{tabular}

\section{Referencias}

AAVV (1999):Elsvalors de La Punta. 18 arguments en defensa de l'borta, Universidad de Valencia. Ajuntament de Valencia (1994): Seminario Internacional sobre la Huerta de Valencia, Ed. Oficina Técnica del Plan Verde, Ayuntamiento de Valencia (realizado entre el 28 y el 30 de abril de 1993)

Alcañiz Moscardó, M. (1996): Cambio social, territorio y actores sociales: La configuración del Área Metropolitana de Valencia, Consell Metropolita de L'Horta, Valencia.

Bordieu, P. (2007): La dominación masculina, Ed. Anagrama, Barcelona (1ª edición en 2000)

Borja, J.; Castell, M. (1997): Local y global. La gestión de las ciudades en la era de la información, Taurus, Madrid.

Cabrejas, M. (1999): "Entrevista a Carmen Gonzáles: La Huerta de la Punta (Valencia)", pp. 83-90, en Revista de Ecología Política $n^{\circ} 17$, Ed. FUHEM / ICARIA, Barcelona.

Capra, F.(2008): La trama de la vida, Anagrama, Barcelona. (edición original en inglés 1996)

Col·lectiu Terra Crítica (2009): Terra Crítica 2001-2007. País, ciutat, ciudadanía, planeta, UPV_UV, Valencia.

Gaja Diaz, F.; Aguza Gimeno, C.(2011): "Els horts d'oci, una alternativa econòmica (i urbanística) per a frenar l'abandó (i l'urbanització) de l'Horta", en Actes del III Congrés D'Estudis del L'Horta Nord. Volum II, pps. 683-700, Editorial Universitat Politècnica de València, pp. 683-700.

García, E.; Cabrejas, M. (1997): València, L'Albufera, L'Horta: MediAmbient i conflicte social, Universidad de Valencia.

Gavaldá, J.; Bayona, V. (2011): “El Pla d'Acció Territorial de L’Horta: Protecció del territori o reserva de sòl per urbanitzar? Una análisi de la superficie i connexions del PATH”, en Actes del III Congrés D'Estudis del L'Horta Nord. Volum II, pps. 627-652, Editorial Universitat Politècnica de València.

Gil Corell, M. (1999): “Aproximació ecológica a L’Horta de València”, en AAVV (1999) Elsvalors de La Punta. 18 arguments en defensa de l'horta, Universidad de Valencia. 
Giobellina, B. (2011):La defensa del suelo agricola de calidad como recurso finito y estratégico para la soberania alimentaria y la sustentabilidad local y global. El caso de la buerta del gran Valencia, Tesis Doctoral, Valencia. 605 páginas. Disponible en internet: http://hdl.handle.net/10251/13616

Glick, T.F. (1988): Regadío y sociedad en la Valencia medieval, Del Cenia al Segura, Valencia.

Glick, T.F. (2003): Regadío y sociedad en la Valencia medieval, Biblioteca Valenciana, Colección Historia/Estudios, Generalitat Valenciana, Valencia.

Glick, T.F. (2011): "What do Spanish Irrigation Systems owe to Arabs, really?", en: Actes del III Congrés D'Estudis de L'Horta Nord, Volum I, Editorial Universitat Politècnica de València, Febrero 2011, pp. 11-16

Granovetter, M. S. (1973): "The strength of weak ties", en American Journal of Sociology; vol 78, nº.(pp. 1360 - 1380). Traducción: Ma Ángeles García Verdasco.

Guinot, E. (2011): “Aproximació a la Historia del paisatge rural de l'Horta de València”, en en: Actes del III Congrés D’Estudis de L'Horta Nord, Volum I, Editorial Universitat Politècnica de València, Febrero 2011, pp. 17-47

Guinot, E. (s/f): El paisaje de la buerta de Valencia. Elementos de interpretación de su morfología espacial de origen medieval, Universitat de Valencia

Horta en Lluita(2006):"La Punta: ahora y siempre contra el invasor. Cooperación desde la diferencia en la lucha contra la destrucción de la huerta histórica en la pedanía de La Punta (Valencia)", pp. 115-128, en AAVV (2006) Los Pies en la tierra. Reflexiones y experiencias hacia un movimiento agroecológico, Virus editorial

Johnson, S. (2008): Sistemas emergentes. O qué tienen en común hormigas, neuronas, ciudades y software, Turner Publicaciones y Fondo de Cultura económica, Madrid ( $1^{\text {a }}$ edición en inglés en 2001)

Martínez-Alier, J. (2009):El ecologismo de los pobres.Conflictos ambientales y lenguaje de valores, Icaria-Antrazyt, Barcelona.

Mies, M., Shiva, V.(1997) Ecofeminismo. Teoría crítica y perspectivas, trad. Mireia Bofill, Eduardo Iriarte y Marta Pérez Sánchez, Icaria, Barcelona.

Mies, M., Shiva, V.(1998): La praxis del ecofeminismo. Biotecnología, consumo y reproducción, trad. Mireia Bofill y Daniel Aguilar, Icaria, Barcelona.

Miralles i Garcia, J.L. (1994): "La protección de la Huerta como estrategia de desarrollo económico del entorno metropolitano de Valencia", en Ajuntament de València (1994) Seminario Internacional sobre la Huerta de Valencia, Ed. Oficina Técnica del Plan Verde, Ayuntamiento de Valencia, pp. 359-364

Montiel, A. (2008): "Els valors de l'Horta: historia, complexitat i futur", en Rev. Eines no 5 , Valencia.

Montiel, A.; García Tobarra, E. (2011): “L'Horta de València. Una realidad metropolitana ignorada", en: Actes del III Congrés D'Estudis de L'Horta Nord, Volum I, Editorial UniversitatPolitècnica de València, Febrero 2011, pp. 579-610.

Torres Castejón, V. (2004 Anexos): Políticas de transporte urbano. El caso del área metropolitana de Valencia, Tesis Doctoral, Departamento de Economía Aplicada, Universidad de Valencia.

Torres Castejón, V. (2004) "Nuevos y viejos movimientos ciudadanos en el país valenciano" (artículo facilitado por el autor)

Torres Castejón, V. (2010): "De los salvem a la defensa del territorio. Los nuevos movimientos ciudadanos, ya no tan nuevos", (artículo Para el libro colectivo en conmemoración de los 15 años de las Jornadas Just Ramírez de debate sobre los movimientos sociales, a editar por la Universitat de València) 
Villasante, T. (2006:) Desbordes creativos: Estilos y estrategias para la transformación social, Catarata, Madrid.

Villasante, T.(s/f): Las matrices y los tetralemas son juegos con la complejidad para hacerla más creativa socialmente, Textos Metodológicos de la Red CIMAS, UCM, http://

www.redcimas.org/

Villasante, T. (s/f): La socio-praxis: un acoplamiento de metodologías implicativas, Textos Metodológicos de la Red CIMAS, UCM, http://www.redcimas.org/

Villasante, T. (2009): “Construir acción-conocimientos colectivos ¿Desde dónde? ¿Para quién? ¿Para qué? ¿Cómo?”, (Des)encuentros Universidad-Movimientos sociales. Un debate con aportaciones. Jornadas Universidad de Granada, España. 